\title{
Chapter 13 Water, Health and Early Warnings
}

\author{
Yahya Abawi, Paul Llanso, Mike Harrison, and Simon J. Mason
}

Following on from the previous Chapter are three contributions that cover the remaining "classical" areas for applications (alongside agriculture) of hydrology and health. Water management is the focus in the first section, in which a number of projects are described whereby historical and forecast information is used directly in planning specific actions; in this case the forecaster-user chain is short and manageable at a personal level. Next is a detailed account of the steps required to establish climate services in the health area. Finally, Early Warning Systems are described. Early Warning Systems have not tended to use predictions until recently, traditionally having been built around historical observations. In that context Early Warning Systems provide an example of an application mainly designed for humanitarian benefit built solely using climate data alongside other information, but with growing use of predictions. A worked example is included establishing the impact of climate variability on disease incidence, the results of which provide a basis for incorporating seasonal climate forecasts into a Malaria Early Warning System in southern Africa.

\subsection{Introduction}

In this chapter experiences in communicating and applying seasonal forecasts in the areas of water management (Section 13.2), human health (Section 13.3), and in early warning systems generally (Section 13.4) are discussed. It is emphasised

\footnotetext{
Yahya Abawi

Queensland Climate Change Centre of Excellence

Paul Llanso

Consultant, ex-WMO

Mike Harrison

Independent Consultant

Simon J. Mason

International Research Institute for Climate and Society
} 
throughout that not only do predictions form only one component of climate information that is of interest in these sectors, but that climate is only one of many factors that influence decisions. As argued in Chapter 2, seasonal climate predictions need to form one component of a broader climate service, involving information at a range of timescales, including monitoring and historical information. This chapter provides examples of the importance of understanding the context within climate information may be used in the respective sectors.

\subsection{Application of Seasonal Climate Forecasting in Water Resources Management}

\subsubsection{Introduction}

This section describes the application of seasonal climate forecasts in water resources management in three different environments: a large scale irrigation system in the Murray Darling Basin of Australia; a medium scale irrigation system in the Indonesian island of Lombok; and small water resources systems in the Pacific Islands. Each case study is described in terms of their unique characteristics and lessons learned from these studies, which may help overcome some of the barriers discussed.

Although advances in climate science and improvements in modelling provide a direct quantification of the benefits and risks of using seasonal climate forecasts in making management decisions, there remain significant barriers to widespread adoption of such forecasting tools. Nicholls (1999) identified the difficulty people have in estimating and dealing with probabilities, risk and uncertainty as being one of the primary barriers. Additional constraints include: understanding probability and probabilistic forecasts and their reliability, lack of integration and evaluation, political and institutional influences, relevance and timing. Most of these barriers to the use of climate predictions represent a lack of knowledge about the forecast and impact systems, a forecast delivery problem, or difficulties in users reacting to the forecasts (Nicholls 1999). One reason why the quality of seasonal forecasts remains an impediment is that decision makers are not only concerned with statistical validity of a forecast from a climatology perspective, but also how reliably a forecast predicts impacts on the systems that are being studied. In a study of subsistence farming in Africa, Hulme et al. (1992) found that individual farmers were unlikely to benefit from forecasts because of poor forecast quality, of having insufficient flexibility to respond, and of the fact that decisions are based on a range of factors of which climate is only one.

In water resources management there are additional impediments that limit the use of seasonal climate forecasts. These include: 
- Dealing with complex systems: water management involves issues of supply, quality, allocation, distribution, reliability and competing demands between consumptive (production) and non-consumptive (environmental) users. Often the development of a hydrological model for a catchment takes several years to calibrate and validate and is unique to each catchment. This validation must be in place before the impact of seasonal climate forecasts can properly be assessed.

- Relevance: climate forecasts mainly focus on prediction of rainfall. In some cases this may be used sometimes to predict impacts on agricultural decisions, such as in subsistence farming where a direct relationship exists. However, the impact on water resources systems is a combination of multiple interacting and complex variables. Forecasts of rainfall may not be directly relevant to water allocation decisions, whereas forecasts of streamflow may have more relevance.

- Lack of hydrological data: hydrological data (e.g. streamflow data) are limited, particularly in developing countries, unlike rainfall data where long-term records, albeit with major gaps in some regions, exist for many locations around the world that are useful for developing climate prediction models. Even where hydrological data exist, they are highly impacted by the construction of dams, weirs and irrigation diversions. To assess the impact of climate variability on streamflow and water allocation decisions we need synthesised or 'natural' records of streamflow where the effect of infrastructure development and irrigation diversions has been removed. These could then be used to simulate various scenarios of development and operational rules within a system.

- External constraints: Legal requirements can often lead to inappropriate and inefficient water use. In many countries, including Australia, water authorities will not allocate irrigation water based on probabilistic forecasts of dam inflows for reasons of litigation. They use a no-risk or zero-inflow scenario when deciding on allocation even where, as discussed later, a strong and statistically significant relationship between ENSO and future dam-inflows exists, e.g. as in north-eastern Australia. This conservative approach to water allocation by water agencies may adversely impact on growers' decisions to increase planting area, resulting in lost opportunities.

Despite these difficulties, significant opportunities exist for applying seasonal climate forecasts in water resources decision making. Catchment scale responses, such as streamflow, can capture the global and regional effects of climate variability (e.g. ENSO) much better than point scale responses such as rainfall. Dutta et al. (2006) found that higher skill (as measured by the LEPS score) was associated with seasonal forecasts of streamflow as compared to rainfall for the same period within the same catchment. Skillful forecasts of streamflow were also possible at longer lead-times (up to 4 months) than for rainfall.

In a study of Columbia River hydropower in the USA, Hamlet et al. (2002) found that forecasts of streamflow with 6 months lead-time can facilitate improvements in the operating performance and can increase energy production by as 
much as 5.5 million $\mathrm{MWh} /$ year, resulting in an average increase in annual revenue of approximately $\$ 153$ million per year.

Bates (2002) identified several key points that need to be taken into account by researchers when dealing with climate forecasting and its application in water resources management:

- The net benefits of using seasonal forecasts in water management have not been demonstrated. This demonstration must take place within operational settings so that the focus is on user needs rather than those of climate scientists.

- Users require objective, explicit and user-friendly forecasts at temporal and spatial scales appropriate to their needs. They also require applicable information about forecasting errors and uncertainty.

- Appropriate mechanisms for technology transfer of climate forecasts to endusers must be in place.

- Socio-economic aspects of forecasting are crucial. For example stakeholders need better education on climate issues and processes, forecasting techniques and probability. On the other hand, scientists need to recognise the effects of institutional, political, educational and cultural constraints on policy formulation and decision making.

- Problems and issues are more complex in developing than in developed countries, because of lack of funding, data paucity, institutional capacity, social capital and lower priority placed for meteorological services, and there is a need to strengthen local meteorological capacities.

- Uptake of seasonal climate forecasts in water resources management would be best achieved through a cooperative approach between forecasters and users.

The following section describes the application of seasonal climate forecasts in water resources management from large-scale irrigation systems in the Murray Darling Basin of Australia and the Indonesian island of Lombok, to small water resources systems in the Pacific Islands. It is not intended to give a detailed account of the models or results, but to highlight salient differences between the systems and suggest possible solutions to addressing some of the impediments to effective implementation of climate forecasting in water resources management.

\subsubsection{Border Rivers Catchment}

A project funded by the Australian Murray Darling Basin Commission examined the use of seasonal climate forecasts in irrigation management and water allocation decisions in the Border Rivers catchment (between $27^{\circ} 30^{\prime}$ and $30^{\circ} 2^{\prime} \mathrm{S}$; $148^{\circ} 39^{\prime}$ and $152^{\circ} 9^{\prime}$ E) in the northern part of the Murray Darling Basin (Fig. 13.1). The key objectives were to answer these questions: 


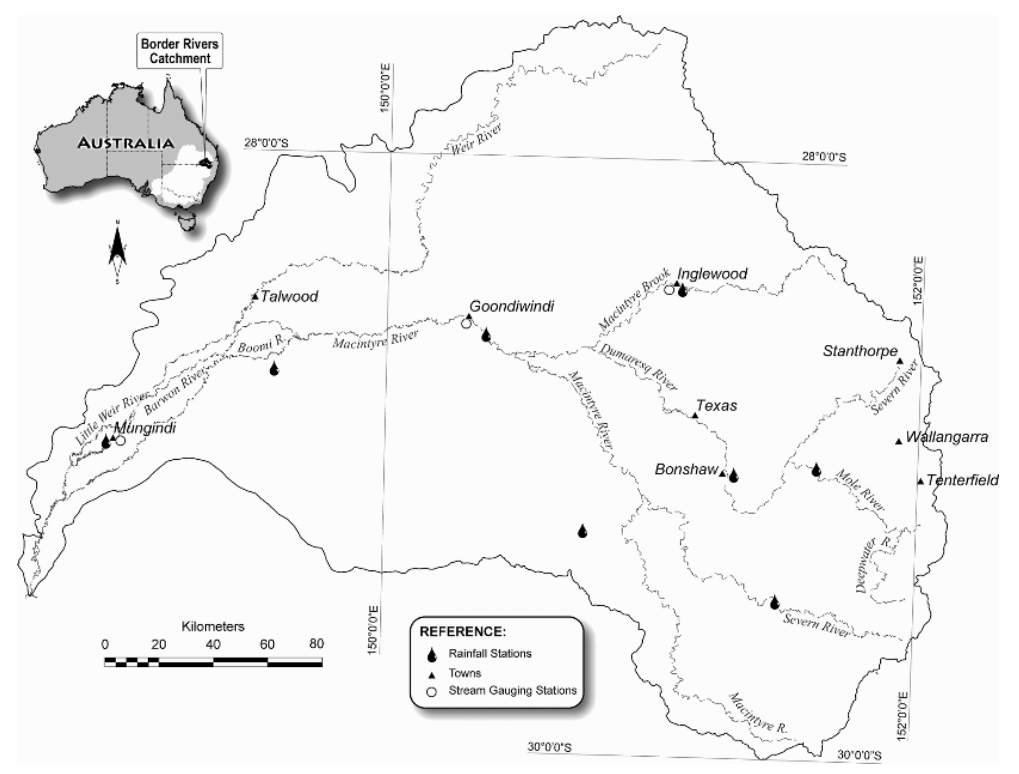

Fig. 13.1 Location of the Border Rivers catchment in the northern Murray Darling Basin, Australia

- Can seasonal climate forecasts lead to improved decision making, and thus higher profits, for growers, by guiding adjustments of areas planted to cotton in each season?

- What is the potential economic impact of seasonal climate forecasts if water managers incorporate climate forecasts in water allocation decisions?

- What is the likely uptake of climate forecast information in decision making by irrigators?

The results of these investigations have been reported by Abawi et al. (2005), Richie et al. (2004), Keogh et al. (2004), and Dutta et al. (2006). In this section the second question is briefly explored as this issue is seen as one of the barriers to the adoption of seasonal climate forecasts in irrigation decision making.

The Border Rivers catchment covers an area of $44,100 \mathrm{~km}^{2}$ with an average annual rainfall of $800 \mathrm{~mm}$ in the east and of $550 \mathrm{~mm}$ in the west. Despite considerable infrastructure development during the last 2 decades, water remains limiting for irrigation due to the high climate variability associated with ENSO, which has a dominant influence on the climate of the region. Irrigated cotton accounts for $83 \%$ of the 53,900 ha developed for agriculture and is planted in early October and harvested in March.

Sources of irrigation water are from announced allocations (expressed as a percentage of an irrigator's licensed entitlement) and from water pumped directly from the river system during periods of high flow (off-allocation). Off-allocation pumping is only permitted when flows in the river exceed certain thresholds set 
for riparian needs and end of system flows. These thresholds are defined in the Border Rivers Water Resources Plan. For example, an annual target of $60 \%$ of mean annual flow is set for end of system flows to ensure downstream requirements are met. Allocations are determined by the water authority just prior to a cropping season and are based on a resource assessment taking into account: (a) the actual amount of water in State-owned storages; (b) high security requirements such as urban, industry, horticulture and dairying; (c) losses such as in delivery, seepage and evaporation; and (d) total licenses issued to irrigators. These allocations may be increased during the growing season if additional flow is received, but for legal reasons the water managers use a zero-inflow scenario when deciding on the allocations.

Risk-averse irrigators will make crop area decisions based on their initial allocation. However, a risk-preferring irrigator may take additional future inflows into account when making his/her decisions. Considering that in this catchment more than $60 \%$ of average annual flows occur after planting, knowledge of future inflow probabilities would be invaluable to farmers contemplating what area to plant. Unfortunately, no mechanism exists to communicate future inflow probabilities to the irrigators. This is a significant barrier to the adoption of seasonal climate forecasts, particularly in north-eastern Australia where the impact of ENSO on rainfall and streamflow is high and the skill in forecasts is moderate to high (Dutta et al. 2006).

To assess the impact of ENSO on dam inflows and water allocation decisions, daily 'natural' flows (1890-1997) for major streams and tributaries were obtained from the New South Wales (NSW) Department of Land and Water Conservation (DLWC) and used in a hydrological model (Integrated Quantity Quality Model IQQM; DLWC 1998) to simulate dam inflows, allocation levels, water availability and other hydrological variables. These simulations were based on the current level of development and operating rules within the catchment.

Relevant hydrological data were extracted from the model output based on analogue years of El Niño, La Niña, and non-ENSO events. An analysis based on these events provided a useful reference of climate extremes. The presence or absence of these events is usually well known by June to September based on sea surface temperature (SST) anomalies in the Pacific Ocean, and can provide sufficient lead-time for decision making.

Using this approach Abawi et al. (2005) showed a median difference in annual inflow between the La Niña and the El Niño years in all state-owned dams within the catchment of 144 gigalitres (Gl). The median difference in inflow in the October-March period (inflows that water managers will not consider in the allocation decisions) was $55 \mathrm{Gl}$. Assuming that $40 \%$ of this water is lost due to evaporation, conveyance and other losses, the net additional volume of water (33 GL) translates to an irrigated cotton area of approximately 5,500 ha or $10 \%$ of the total area developed in the catchment. The additional value of this water based on the current price, yield and water requirements of cotton is about $\$ 16$ million. The socioeconomic impact of this additional water in employment and its multiplying effect 
on the regional economy could be in the order of two-three times or up to $\$ 45$ million. The results presented here were based on the median flow, however, it can be repeated for the mean or other percentile values of the flow and could be used as a risk management tool.

To overcome the legal barrier faced by water managers, a possible solution would be to simulate allocations levels, based on seasonal climate forecasts, at the beginning and end of a cropping season and make these results available to irrigators. These results based on El Niño and La Niña events are given in Abawi et al. (2005), but could be reproduced for any climate predictors (e.g. SOI) and predictands (e.g. streamflow, allocation, rainfall). An example of the results from that study shows a $50 \%$ chance that during a typically dry El Niño year the allocation may be increased from an initial $28 \%$ to a final of $60 \%$ of the irrigator's license entitlement (corresponding results for La Niña years shows an increase from an initial $74 \%$ to a final of $100 \%$ ). If appropriate dialogue can be established between water managers and water users, and the information on future inflows could be communicated on an all-care-but-no-responsibility basis, growers may incorporate such information into their decision making process. This shift of risk from water managers to water users would alleviate the legal issues faced by the water managers and pave the way for the adoption of climate forecasts in decision-making by the irrigators. Obviously the uptake of such information would ultimately depend on many factors including the type of enterprise, farm size, commodity price and future markets, financial position and an individual's attitude to risk.

To determine the factors that influence farmers' decisions and whether they would use seasonal climate forecasts in their decisions, a mail survey was sent to 931 irrigators involved in agricultural production from regulated water supplies in the Border Rivers, Gwydir, Namoi and upper Condamine catchments of the Murray Darling Basin. The questionnaire was designed to obtain information about general farm characteristics; irrigators' knowledge of the climate system including relationship between El Niño/Southern Oscillation and rainfall/streamflow; how irrigators make cropping and water decisions; who they consult; and information sources and use of computer technology. One hundred and seventy responses were received from the survey and the results described in (Keogh et al. 2004). The results show that almost $67 \%$ of irrigators access seasonal climate outlook information, but only $20 \%$ are sufficiently confident to apply this in their decisions. Almost 75\% would change their crop area, and $43 \%$ their crop type, if given advanced information on probable water availability up to 4 months ahead of the irrigation season. The likelihood of climate-related decision making increased substantially with the size of the farm and type of enterprise (cotton farmers vs non-cotton farmers). Forecasts appear to be particularly useful for cotton growers; $80 \%$ of them were prepared to consider changing their crop area, compared to $45 \%$ of non-cotton growers. Farmers with more than 600 ha of irrigation are twice as likely to use climate forecasts in decision making than farmers irrigating less than 100 ha. 
Risk-averse farmers are unlikely to incorporate seasonal climate forecasts in their decision making. The level of risk-aversion is inversely proportional to the level of wealth (Anderson et al. 1977), an observation which supports the findings of this survey that likely users of seasonal climate forecasts are large corporate irrigators and farmers.

To communicate results and to seek irrigators' and water managers' input to the research process, effective dialogue between irrigators, researchers and water managers was established through a steering committee, and regular meetings held during the progress of the project. This formative evaluation (evaluation during the life of the project) was used to gather information that may help identify factors that contribute to successful or low uptake of the research. In response to this feedback, regular monthly articles were published in local newsletters with updated information on streamflow forecasts, the general climate outlook and on understanding basic forecast terminology. The survey by Keogh et al. (2004) was conducted 3 years after the project commenced. The improved level of climate knowledge gained by irrigators is possibly a reflection of this cooperative approach.

\subsubsection{Indonesian Island of Lombok}

A similar study to that in the Murray-Darling Basin, funded by the Australian Centre for International Agricultural Research, ${ }^{1}$ is being conducted on the island of Lombok in Indonesia to develop hydrological and crop models to assess the value of seasonal climate forecasts in water allocation and irrigation decisions.

Lombok lies in the eastern part of the Indonesian Archipelago and is situated between $8^{\circ} 12^{\prime}$ and $9^{\circ} 01^{\prime} \mathrm{S}$ and between $115^{\circ} 46^{\prime}$ and $116^{\circ} 43^{\prime} \mathrm{E}$, covering a land area of approximately $4,800 \mathrm{~km}^{2}$. The climate of Lombok is tropical and it is possible to grow three successive crops (usually rice, rice, secondary crops) each year provided water is not limited. Most rainfall occurs in the wet monsoon season 'Musim Hujan' from November-March followed by the dry season from AprilOctober. Seasonal and inter-annual rainfall variability is strongly influenced by ENSO. More than $90 \%$ of droughts in eastern Indonesia are associated with El Niño events. The influence of ENSO on the climate of Indonesia is described by Haylock and McBride (2001).

Rice is the dominant irrigated crop grown on the island. Whilst irrigation infrastructure is well developed water use efficiency is low, and large parts of the island experience water shortages due to inadequate supply and distribution of irrigation water, particularly in El Niño years.

\footnotetext{
${ }^{1}$ See: http://www.acair.gov.au
} 
The approach used in assessing the utility of climate forecasts is similar to that described in the Border Rivers catchment. A significant difference in hydrology and water management issues in Lombok from the Borders River is that most rivers are un-regulated, with little storage upstream of irrigation areas. Therefore prediction of streamflows during the irrigation season is of higher importance for effective irrigation decisions and water allocations than in the Australian case.

Water availability throughout the irrigation system was modelled using the IQQM model and a Linear Programming Model (LPM) was developed to optimize cropping decisions under different climate, water, land and institutional constraints. A detailed description of the models, data issues and methodologies is given in Abawi et al. (2002). In this section some of the issues which are likely to impact on the adoption of seasonal climate forecasts in developing counties such as Indonesia are highlighted.

- Understanding the socio-economic culture in developing countries is crucial for successful adoption of climate information. Rice is grown more for its social value than for its economic value. The Indonesian Government encourages farmers to grow rice for self-sufficiency reasons. Farmers prefer to grow rice than any other crop because it provides the staple diet and can be stored on their farms for long periods, providing a buffer against crop failure in some seasons. Farmers' preferences, as well as those of the Government, must be incorporated in the development of decision support models.

- Understanding of markets, as well as of supply and demand issues, is very important. Rice requires twice or three times the amount of water to grow than other crops which may have a higher market value. In decision support models (e.g. LPM) if profit maximisation is the primary goal, crops such as chilies, vegetables and tobacco may be the preferred solution because of their higher value and lesser demand for water. However, in a closed market there is little opportunity for export, and market saturation will result in a sharp drop in prices causing financial losses to the farmer. Government regulations limiting the production of certain crops such as tobacco must also be taken into account as part of an overall solution.

- An average farm size in Lombok is about 0.25 ha (cf. 600 ha in the Border Rivers catchment). Most farmers are risk-averse, preferring less risky sources of income in order to reduce the possibility of loss. Therefore little visible opportunity exists for adjusting cropping patterns at the individual farm level based on climate forecast information. However, significant economic gains can be made through water allocation and cropping decisions at a scale that integrates the characteristics of many of these smaller farms. Water is allocated to each irrigation area by a committee of irrigators and government advisors. Input from government advisors with knowledge and access to climate forecasts is crucial to the success of these decisions. 
- Strategies such as water pricing and water trading which are often adopted in developed countries in response to water shortages, such as those during an El Niño, are unlikely to be acceptable in Indonesia due to cultural and religious beliefs.

Other issues which may affect potential use of seasonal climate forecasts in agricultural decisions on the Indonesian Island of Lombok were identified in a survey by Sayuti et al. (2004) and include:

- Farmers have a low level of education; $75 \%$ have never been to school or have received only elementary schooling.

- A propensity for farmers to believe traditional forecasts (e.g. astrology and indigenous knowledge such as the flowering times of trees, movement of insects and wildlife) rather than scientific information such as forecasts based on ENSO.

- About half of the farmers in Lombok believe the advice of the government on water availability and crops to plant.

- $40 \%$ of farmers may change crop type if the government advises of an impending shortage or excess of water in the coming season.

Educational attainment levels influence the ability to adopt innovative processes and have significant implications in the development and implementation of action plans dealing with technology transfer. The survey in Lombok also showed a strong dependence by the farmers on advice from the government. This provides significant opportunities for working with government agencies, in addition to farmer groups, to successfully implement results, as government agencies also control water allocation and, in some cases, seed allocation. The role of government in the implementation of new programs has been used in Indonesia during the green revolution when the Indonesian army helped in the spread and adoption of new and improved rice varieties while farmers initially resisted the change.

In summary, social and cultural issues in developing countries are just as important as the science of seasonal climate forecasting. Forecasts must be reliable and skillful before anything can be done, but if the social, cultural and educational issues are ignored, prediction technologies are unlikely to be adopted.

\subsubsection{Pacific Islands}

Similar climate-related issues to those discussed for north-eastern Australia and Indonesia exist in the Pacific Islands. Drought is one of the major hazards facing Pacific Island nations, is strongly related to ENSO events on many islands, and can have severe impacts throughout the region. The drought impacts of the 199798 ENSO event have been well documented (Glantz 2001). Lessons learned from the 1997-98 droughts in the Pacific demonstrate the need for effective and 
timely forecasting and warning systems, drought response strategies, information on quantitative measures of drought, improved water management and improved crop and stock management.

Despite their vulnerability to the impacts of climate variability, most Pacific countries have limited meteorological service capacity to provide timely climate forecasts for their climate sensitive industries. In 2002 the Australian overseas aid agency, AusAid, funded a project to improve local meteorological capacity by developing climate forecasting software and by providing training for meteorological service staff and stakeholders from agriculture, water, health, fisheries, and disaster management. A further objective of the project was to evaluate the utility of seasonal climate forecasts in the management of water resources in selected countries.

Climate prediction software, called SCOPIC (Seasonal Climate Outlooks for the Pacific Island Countries ${ }^{2}$ ), was developed based on the operational seasonal climate forecasting system used by the Australian Bureau of Meteorology. SCOPIC produces forecasts based on the relationships between SST anomalies in the Pacific and Indian Oceans with rainfall or other hydro-meteorological variables on Pacific islands. Training in the use of the software, on climate issues and processes, and on forecasting techniques and basic statistical concepts such as probability and data analysis, was provided in a series of workshops in nine Pacific Island Countries (Fiji, Vanuatu, Tonga, Samoa, Cook Islands, Solomon, Kiribati, Tuvalu and Niue). Feedback from these workshops was used in the design of the software to meet the requirements of Meteorological Services and other stakeholders. Experiences from the workshops which may help in forecast preparation, delivery and the adoption of seasonal climate information, are discussed below.

Understanding the strengths and weaknesses of a forecasting system by users can engender user confidence in the forecasts. Unfortunately many climate forecasts issued by Meteorological Services to the public focus only on the probability of certain rainfall events, and errors and uncertainties of forecasts and forecast skills are not explicitly communicated. Visual presentations can help in the understanding of complex climate concepts, particularly when users do not have a detailed understanding of scientific issues. An example of such visual presentations is illustrated in Fig. 13.2, which shows the skill of seasonal climate forecasts in Kiribati (left) and in the Solomon Islands (right). Skills of forecasts for successive 3 month periods are expressed using LEPS scores (Linear Error in Probability Space; Potts et al. 1996) along the $x$-axis for different lead-times ( $y$-axis). Shades of blue indicate more skill than climatology, while shades of red indicate less skill than climatology. This snapshot presentation is helpful in assessing when a forecast is useful and when it is not. For example, prediction of rainfall has moderate to high skill throughout the year in Kiribati with relatively long lead-times. On the

\footnotetext{
${ }^{2}$ See: http://www.bom.gov.au/climate/pi-cpp
} 
other hand, in the Solomon Islands, there is good skill during November to March (wet season) but no skill from April to August (dry season). Understanding the strengths and weakness of a forecast can reduce the uncertainty associated with using climate forecasts in decision-making.

Users are more likely to appreciate the real levels of skill if these are explained using a time series of how the forecast would have performed in the past (hindcast), showing when they work and when they are unreliable. This approach may also help in communicating concepts such as 'probability' as most people understand frequencies (e.g. number of consistent forecasts from a total number of forecasts issued) better than probabilities. This is illustrated in Fig. 13.3 for the forecasts of June-July-August (JJA) circled in Fig. 13.2. It shows a time series of crossvalidated hindcasts for the period in question. In cross-validated analysis, data for predicted periods are omitted successively from the model to avoid model bias. Here forecasts are expressed in terciles, i.e. the probability of rainfall being belownormal (tercile 1), normal (tercile 2) and above-normal (tercile 3). Although in a probabilistic forecast all eventual outcomes within a forecast pdf are possible, users' expectations of such forecasts are that the likely outcome would be within the tercile with the highest probability, particularly when these probabilities are significantly higher than climatology. To illustrate this, for each year of analysis, a blue bar is used in Fig. 13.3 to indicate that the observed value of rainfall was in the same tercile as the tercile with the highest probability (consistent forecast). A red bar indicates that observed rainfall was different by two categories from the most probable (inconsistent forecast), and yellow bars indicate that observed rainfall was in the neighbouring category (near consistent forecast). This illustration helps in understanding the frequency of observed rainfalls being within a user's expectation of a forecast. It also demonstrates that from the user perspective the utility of a forecast is not uniform and it is possible to a have a long sequence of 'consistent' forecasts (in the sense that observed rainfall lay in the predicted highestprobability tercile) followed by a succession of 'inconsistent or near consistent' forecasts.

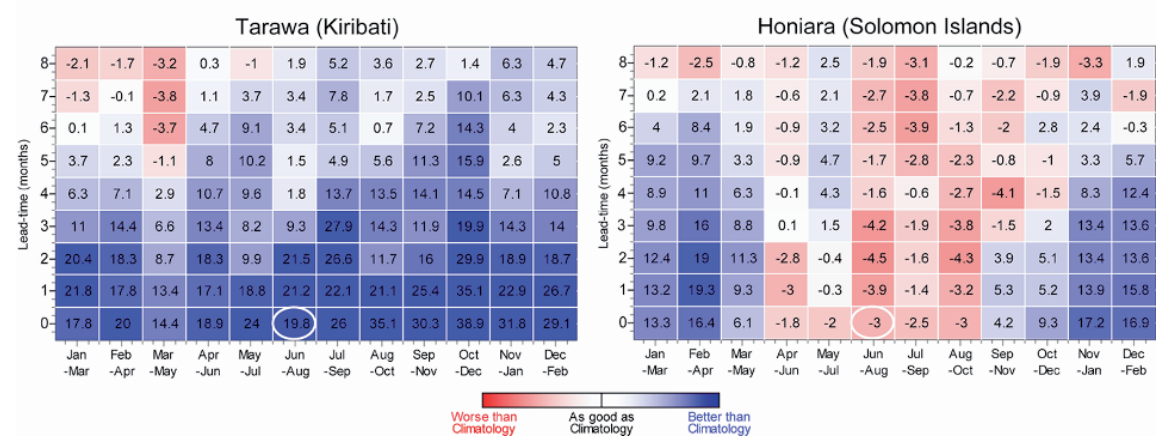

Fig. 13.2 LEPS scores for 3 month rainfall forecasts based on SST anomalies in the central eastern Pacific and the Indian Ocean. Kiribati (left); Solomon Islands (right) 

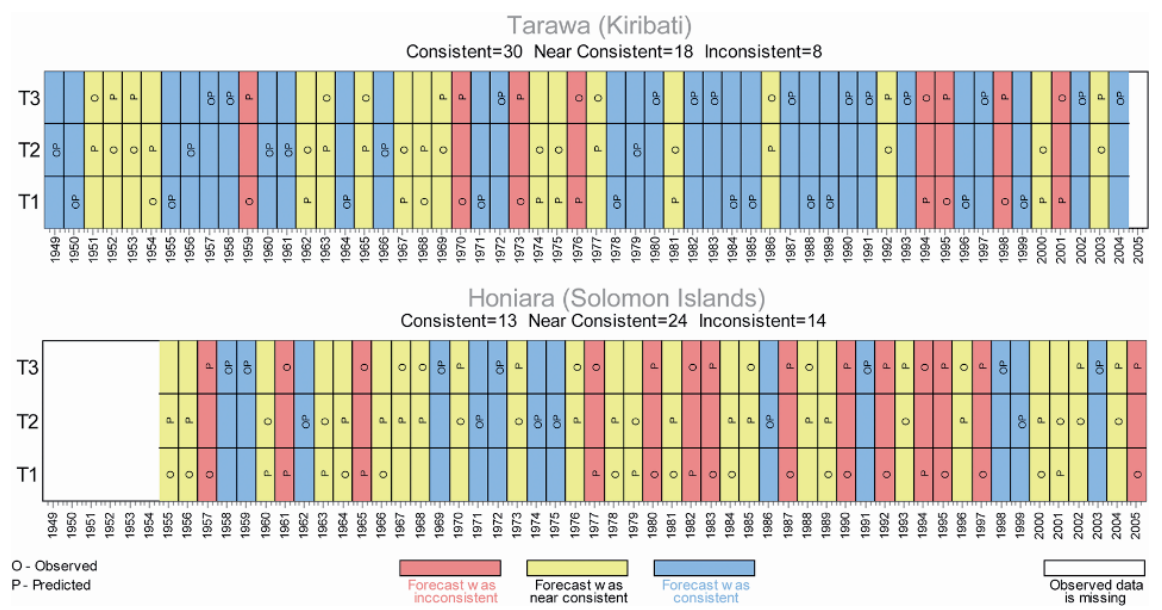

Fig. 13.3 Cross-validate hindcast analysis of a 3 month rainfall forecasts based on SST anomalies in central eastern Pacific and the Indian Ocean. Kiribati (top); Solomon Islands (bottom), T1, T2, T3 are rainfall terciles. $\mathrm{P}$ denotes tercile with highest forecast probability. $\mathrm{O}$ denotes tercile with observed value of rainfall

User expectations are often different from those of forecast providers. Forecasts produced by Meteorological Services usually offer a 3-month rainfall outlook based on current values of key climate predictors. In many applications, however, forecasts of different durations and lead-times are needed. For example, in Fiji monthly forecasts of rainfall are needed to plan effectively for fertiliser application to sugar crops. This mismatch between user needs and what is currently available from forecasting systems is likely to limit the use of seasonal climate forecasts in certain applications, and provides a real challenge for the developers of climate forecast systems to tailor forecasts that meet user requirements.

The second aim of this study in the Pacific Islands was to evaluate the utility of seasonal climate prediction in the management of selected water resources. On small islands, the main use of water is for domestic purposes and water is obtained either from rainwater tanks (e.g. Tuvalu) or shallow groundwater sources (e.g. Kiribati). In these simple hydrological systems there is a direct link between historical rainfall trends (ranging from a few months to a few years) and the status of water resources (such as the volume of water in tanks, groundwater salinity or the volume of shallow fresh groundwater lenses). Thus rainfall periods (totals) used in climate analyses depend on the 'hydrological residence time' of the selected water resource system. For example, rainfall totals over a 2- or 4-month period may correlate with water supplies in rainwater tanks (e.g. Funafuti in Tuvalu), while rainfall totals over a 30-month period may better reflect the volume of groundwater lens (e.g. Tarawa in Kiribati). 
Analysis of past rainfalls can be used to monitor the status of these resources and actions taken once pre-determined thresholds are reached. White et al. (1999) used rainfall ranking (rainfall percentiles for different periods) to define 'drought' in a manner relevant to domestic water supplies on the Pacific Islands of Tuvalu and Kiribati. A time series of rainfall percentiles (over a time period appropriate to the system under study) can be used to warn of impending drought (e.g. when percentiles fall below 40\%) or severe drought periods (e.g. when percentiles fall below 10\%). Using these definitions historical droughts can be identified and related to climate episodes. Statistics on past correct warnings (i.e. when the $10 \%$ threshold is reached following the warning threshold of $40 \%$ ) and false warnings (i.e. the threshold of $10 \%$ was not reached after the preliminary warning), in conjunction with the current status of ENSO, can be used to develop appropriate early warning and water management strategies. Past strategies to deal with the impacts of droughts on water resources have included restrictions on water supply, raising consumer awareness about the need for water conservation, and transportation of water or emergency use of desalination systems.

The drought identification method based on percentile ranking of rainfalls for different periods has been incorporated in the SCOPIC software, and the potential utility of this method as an early warning system is illustrated through an example of the 1997-98 El Niño in the Solomon Islands and Kiribati. The results are shown in Fig. 13.4 for both Kiribati and Solomon Islands, but are discussed here only in the context of drought for the Solomon Islands. In the Solomon Islands, a warm phase of ENSO (El Niño) is associated with drier conditions, whereas a warm phase of ENSO in the Kiribati is associated with wetter conditions because of its location further east in the Niño 3.4 pool of water in the central-eastern Pacific Ocean. This is illustrated in Fig. 13.4 by rainfall being out of phase in these countries for the El Niño of 1997-98 and La Niña of 1998-99.

In Fig. 13.4 is shown the time series of 6-month rainfall percentiles from 1995 to 1999, covering the El Niño event of 1997-98 and the La Niña event of 199899. The time series shows a sharp decline in rainfall percentiles from August 1997 (onset of El Niño) to February 1998, and for most of this period rainfall was below the $10 \%$ (severe-drought). Based on this information a drought warning could have been issued in August 1997 when the rainfall percentiles fell below 40\%. Statistics on the success rate of past warnings in similar climate patterns, combined with forecasting of future rainfall, could then be used to implement appropriate drought management strategies. This is illustrated in Fig. 13.4 for SON, NDJ and JFM forecasts based on SST anomalies in the Pacific and Indian Oceans. The forecasts for the Solomon Islands (and similarly in Kiribati) capture the progress of the 1997-98 El Niño particularly towards the end of 1997 when 


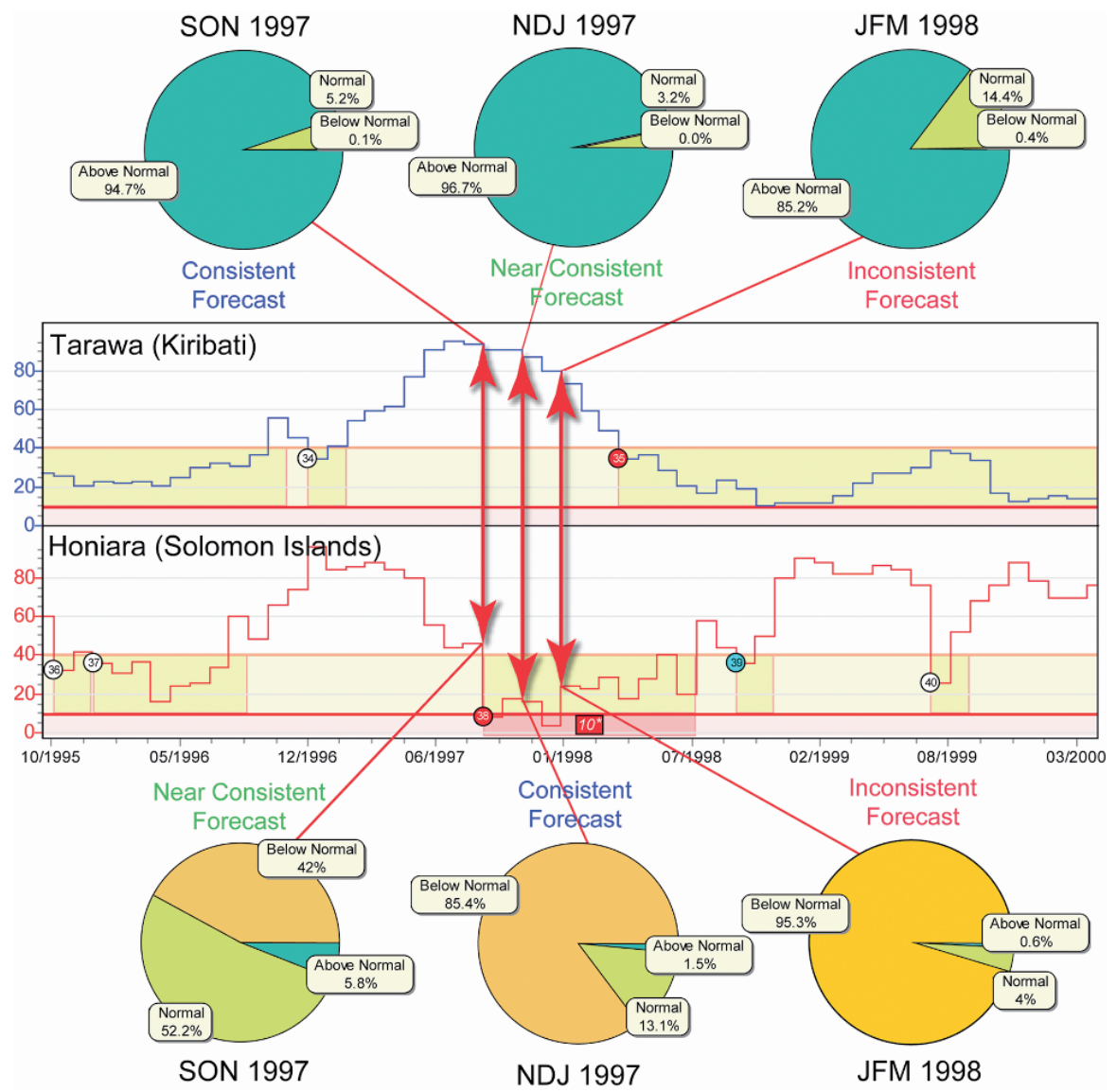

Fig. 13.4 Six-month rainfall percentile values and 3-month rainfall forecasts during the El Niño-event of 1997-98. Pie charts represent probability of above-normal (aqua), normal (yellow), and below-normal (orange) rainfall

ENSO is mature (see SST maps ${ }^{3}$ ). Tercile forecasts of rainfall, i.e. chances of below-normal:normal:above-normal for SON and NDJ were 42:52:6 and 86:13:1 respectively, which shows a high probability of below-normal rainfall particularly later in the year. Knowing the skill of forecasts during this period of the year (Fig. 13.2), decision makers could be confident on the basis of this knowledge of implementing appropriate strategies to deal with the hazards. Specific decisions will depend on the particular country and system. Research in various aspects of water management on the Pacific Islands is currently in progress.

\footnotetext{
${ }^{3}$ See: http://www.nrm.qld.gov.au/longpdk
} 


\subsubsection{Conclusions}

Climate variability has a significant impact on water resource systems ranging from small water supplies for domestic consumption to large scale irrigation systems; however, opportunities for applying climate forecasts in water management decisions are not fully utilised. A number of impediments to the use of climate forecasts have been identified, including forecast accuracy, dealing with probabilities, risk and uncertainty, impact assessment, legal and institutional barriers, lack of integration, and communication. Possible solutions to some of these impediments have been suggested using the three case studies in the Asia-Pacific region. These include engagement of users in the research process, formative evaluation of research outcomes, communicating forecasts in a manner understandable to the users and demonstrating the benefits of forecasts relevant to the system being investigated. While it is clear that no single solution will fit all systems, indeed the treatment of all systems as homogenous has played a significant part in the lack of technology transfer and adoption in the past, prioritization of these issues (impedements) may reveal a starting point to increase the use of climate forecasts in water management decision making.

Clearly, forecast skill must exist before progress can be made, however, skill in a forecast system does not guarantee successful adoption. A perfect forecast will not have an impact unless it can lead to changes in decisions. Engendering user confidence in forecasts remains a high priority. For this to occur, the value of forecasts must be demonstrated through integration of forecasts with impact systems. Given the complexity of water resource systems, Einstein's quote "Make things as simple as you can, but no simpler" is a good guide to where we can begin with integration of climate systems, hydrological models and impact assessments.

The way forecasts are communicated influence their acceptance. Most users have difficulty in understanding probability but are comfortable if information is expressed in terms of frequency. The SCOPIC software was designed to overcome these difficulties in communication by providing a range of options for the user which has led to its wide acceptance in the Pacific region.

Building local capacity helps breakdown institutional barriers by raising profile of meteorological services in the community, establishes user confidence, and improves integration between science and management and the breakdown of communication barriers. This is a priority that needs to be addressed by leading institutions and governments around the world particularly in developing countries that are most vulnerable to impact of climate variability and climate change.

ENSO has a strong footprint in the region described by the three case studies which helps overcome the first barrier (forecast accuracy) and paves the way for impact assessment to be carried out. Forecast skill must exist for benefits to be demonstrated, but if the social, cultural and educational issues are overlooked these prediction technologies are unlikely to be successful in producing outcomes. 
The three case studies have highlighted the importance of engaging stakeholders and the end-users in the research process, hence gaining ownership of the concepts, and helping in technology transfer.

\subsection{Applications of Seasonal Forecasts to the Health Sector}

We urge ministries of health and other ministries, as well as research institutions, to improve our understanding of the regional and national burden of disease due to weather and climate extremes and to identify effective and efficient interventions, such as early warning systems, surveillance mechanisms and crisis management. WHO 2004a

This section examines how climate information is being applied to one of the most important areas of human existence: human health. In Section 13.3.1, some of the basic relationships between climate and health are identified. Section 13.3.2 then explores the issue of acquiring and preparing data for the study and modeling of the relationships as well as the conduct of routine operations that employ that knowledge. It concludes with recommendations on establishing operational services that incorporate the knowledge into public health services.

The goal of this section is not simply to describe the status and future prospects for the use of climate information in one important branch of human experience. Instead, it is to motivate climate modelers, climatologists, and those who are perfecting climate prediction to apply their knowledge and skills in creating concrete actions to diminish human misery.

\subsubsection{Basic Relationships Between Climate and Human Health}

As mentioned by Thompson and Perry (1997) and others, climate information is applied every day to many areas of human activities besides health, including energy, water management, agriculture and forestry, fisheries, urban and building, recreation and tourism, financial services, and transportation. But the focus in this chapter on human health makes the topic especially relevant to readers of this book, and the examples given are generally useful in understanding the procedures involved in the development and implementation of all climate applications. Applications in climate and health generally address four aspects of the human condition: disease, performance, comfort and attitude. While the last three areas are important and fit within a definition of health, most nations' health priorities are in the reduction of disease impacts.

This section deals with diseases that have been shown to have a relationship with climatic conditions and their changes that fall into two categories: infectious 
diseases such as malaria, dengue fever, meningitis, Lyme disease, West Nile virus, St. Louis encephalitis, and Murray Valley encephalitis; and, non-infectious diseases, which include heat stroke, skin cancer, allergic rhinitis, and some diseases of the eyes.

Malaria killed more than a million people in 2003, primarily in developing countries. Climate relationships are strongest in the life cycles of the vector Anopheles mosquitoes - and of the parasite - Plasmodium falciparum being the most lethal (Thomson et al. 2004b). Lack of, or overabundance of precipitation can severely restrict the pools and stagnant ponds that are habitats for the mosquito's juvenile stages, and ambient air temperature directly affects the growth cycle of the parasite within the adult mosquito. The variations in climatic factors associated with El Niño events show some correlation to malaria outbreaks, and the scientific knowledge about the relationships is used in modeling the life stages of the parasite and the vector with respect to climate parameters. That, in turn, is one basis of a Malaria Early Warning System (Section 13.4.2) that can help to focus malaria control methods, which promise to reduce outbreaks and reduce the costs of control efforts.

Pathogens that incubate and develop outside the host (e.g. vectors such as the tick or mosquito) are usually susceptible to climatic conditions to some degree (WHO 2004b). The pathogen that carries malaria needs ambient temperatures of about $17^{\circ} \mathrm{C}$ to begin to develop within the mosquito. And, higher temperatures than that will cause the pathogen to develop more quickly, potentially allowing the mosquito's bites to infect more people.

Climatic variations will influence the distribution and development rate of the vectors, too, affecting such aspects and activities as the metabolic rate, egg production, and the rate of blood meals, as well as the characteristics of the vector itself. Rainfall extremes can affect the vector's habitat - too much may wash away habitat sites, but excesses that are somewhat below that amount can give the vector many more places that stay viable longer, permitting more eggs to develop. Decreased humidity usually means decreased vector life, and can be modeled for some vectors using saturation vapor pressure. Less rainfall usually means fewer useful habitats - small pools shrink to become unviable to maintain growth of the vector in its juvenile stages. While vectors that need conditions of fast moving waters may see their habitat diminish in periods of rainfall deficit, in a small number of cases other vectors that like still water may find their habitat increased, as the drying and slackening of streamflows may leave behind perfectly useful breeding pools. In general, though, more rainfall equals more useful habitats and vice versa.

Increased habitat can increase the geographical distribution of vectors. So, if rainfall can be correlated with specific vectors' habitat, and rainfall variations can be adequately predicted, projections can be made of what is likely to happen to vector distributions geographically and seasonally. While climate information is hardly the key to cures in infectious diseases, it can be a beneficial component of 
the control of the vectors and pathogens, and in some cases, in the treatment of the disease.

Climatic variations play an important role in some non-infectious diseases. The human body can withstand considerable external heat as long as it can dissipate the heat it generates internally, through thermoregulatory processes (WHO 2004a). It normally does this through convection, conduction, respiration, radiation and evaporation of sweat. But when the amount of incoming heat is high enough and the evaporative cooling produced by sweating is overwhelmed, the amount of body heat builds up, and heat illnesses can result. For example, heat related deaths rose dramatically across much of Europe in 2003, when the number of hot summer days was far above the long term average (WMO 2004). Climatic factors that most influence human health include air temperature, solar radiation, humidity, and wind speed.

\subsubsection{Digging and Cleaning Datasets}

"Enhanced planning and decision making is a fundamental capability, at all levels, for the prevention or mitigation of the negative impacts that are often associated with natural hazards. To that end, increased accuracy and reliability of information on weather, climate and water on a global scale and the free, unrestricted and timely access to that information, are some of the requisites for effective natural disaster risk assessment, vulnerability analysis, preparedness and response." Michel Jarraud, Secretary-General of the World Meteorological Organization, in his statement to the World Summit on the Information Society.

Global health depends on the choices we make collecting and using information. Tools, methods and policies for managing information shape our ability to detect health problems, identify solutions and deliver effective interventions. As we leverage this new commitment [to invest in both the developing and industrialized worlds in strengthening data collection and management], we have learned several important lessons: first, there is an urgent need and opportunity to extract, analyse and use existing data across institutional and administrative boundaries; second, users must be enabled to interact and query their data instead of simply collecting volumes of printed reports; and, third, countries need help in communicating with politicians and the media to make it clear that better information is in the mutual interest of the government and its citizens. - Dr Sally Stansfield, Executive Secretary of the WHO-hosted Health Metrics Network (former Associate Director for Global Health Strategies of the Bill \& Melinda Gates Foundation), introducing the HMN Strategy and Plan of Operations for 2007/2008.

Recognizing potential relationships between climate and other environmental components, on the one hand, and disease pathogens (and vectors) and humans on the other, depends on the availability of observations of the components and their 
resulting responses. Modelling those relationships depends on observations, as does the development and testing of operational services based on the models. Even the prediction of the evolution of a climate-sensitive disease, and related predictionbased early warning systems, require observations. And, the assessment of the quality and appropriateness of the outputs of those services depends on observations.

This section addresses the following questions:

- What observational data do you need?

- Where can you get it?

- What problems are there with it?

- What can be done about the problems?

\subsubsection{What Observational Data do you Need?}

In the context of human health, the data will be related to diseases, their impacts in humans, and related societal factors. Epidemiological data are needed to understand the causes of diseases and the factors that determine their distribution. Public health administrative data will describe the evolutions of epidemics, the clinical practices that are employed as well as the periods of the practices and results of treatments, and the control practices and their results. Data on the status and evolutions in a country's or region's infrastructure may figure into the understanding of the capacity and means that were or are employed in the control and treatment activities, as well as describing the variations and status of land use practices and other aspects of human activity that have a relationship with variations in vegetation, climate and diseases. And demographic data will provide information on population characteristics that affect vulnerability to diseases.

Climate and environment data will describe the weather, water, biological and terrestrial variations and status that may influence the diseases. Weather data will include traditional surface and upper air observations of elements including air temperature, rainfall and other forms of precipitation, humidity, wind, and solar radiation, and related elements such as visibility and suspended dust. Hydrological data will provide the status and trends of streamflows, rivers and lakes, and river basins. Oceanographic data will provide information on sea surface temperature and bathymetric profiles, as well as wind structure. Remotely sensed data will provide information on meteorological elements such as precipitation, cloudiness, humidity, snow and ice cover, solar radiation, wind, sea surface temperature and sea levels, and will also provide information on the status of vegetation. Forecast model output will furnish analyses and predictions of many of those variables, at varying grid resolutions. Geographic data will be needed to address the location, elevation, slope and aspect of study sites as well as the boundaries with water masses; and land use data will provide information on desertification, cultivation and irrigation practices, urbanization, and infrastructural changes that influence diseases. 


\subsubsection{Where Can You Get the Data?}

Health-related data depend on the approaches to disease surveillance and the quality, quantity and completeness of the disease data. Data that describe diseases are often provided in the standard format of the International Classification of Diseases (ICD) and Related Health Problems. The best case will be in situations of notifiable diseases, especially where they are subjected to well-resourced surveillance programmes. The researcher in that case may find well documented, logically aggregated, consistent, and relatively complete data through the Ministry of Health. "In other situations, existing systems may need extensive modification, either in the way in which disease data are collected (e.g. diagnostics), or the manner in which data from individual health facilities are collected, aggregated and communicated to higher levels in the health system." - WHO 2004b. To capture information from disease outbreaks over small geographic areas or time periods, one may have to contact public health offices, municipal hospitals or individual clinics. Other sources include academic literature and WHO Regional Offices. The search for societal data can follow similar routes through respective national ministries at one end and literature searches at the other.

Climate and environmental data usually have fairly well centralized and structured archives and observational networks. The National Meteorological and Hydrological Services maintain the most comprehensive datasets for their nations' historical surface and upper air observations. They also participate in daily global data exchange of current observations through the WMO's Global Telecommunications System. The specifics of the available data and the method of acquiring it may be obtained from the WMO Permanent Representative (PR) of the country or territory where the disease is located, or the PR of the country or territory where the researcher is located. Aggregated data of lower resolution may reside at WMO Regional Specialized Meteorological Centres, and may be requested through the PRs noted above. The WMO also coordinates the international archive of globally exchanged hydrometeorological data (traditional as well as remotely sensed) through the World Data Centres in the United States (Asheville, North Carolina) and the Russian Federation (Moscow). Special datasets of very high resolution may also be acquired through academic researchers, scientific organisations and the scientific literature. Searches through Internet web sites often can find relevant datasets that may be downloaded directly, or which may be provided through correspondence with the owners. For example, the European Climate Assessment project makes available quality-controlled climatic datasets from within its region. ${ }^{4}$

\footnotetext{
${ }^{4}$ See http://eca.knmi.nl
} 


\subsubsection{What are Some Problems with the Data?}

Researchers frequently encounter problems with observational data related to health, demographics, land use, infrastructure, environment, etc. The WMO generally classifies problems in hydrometeorological datasets into four categories (WMO 2003b):

- Inhomogeneity

- Variations and unreal trends due to changes in instruments, sensors or processing equipment, observing or reporting practices, station locations, formulae, station environments (and changes in sensor algorithms or drift).

- Inaccuracy

- Variations due to irregular staffing, deteriorated or failed equipment, imprecise reporting of location or elevation, improper encoding or decoding.

- Erroneous data

○ Errors in dataset identifiers, algorithms, transmission, transcription, encoding.

- Missing, incomplete or insufficient data

- Missing due to limited observing programme, failed sensor platform or sensor, data exchange policy or practice

- Incomplete due to non-digitized data, gaps due to civil conflict or disaster, inhomogeneity

○ Insufficient due to resolution in time, space, parameter set

Researchers frequently face similar problems with health data, compounded greatly by the absence of coordinated procedures for near-real time data collection and database management on all scales (sub-national through global scale).

\subsubsection{What Can be Done About Data Problems in Climate- and Health-Related Datasets?}

The following procedures are taken from the experience of WMO in handling traditional surface and upper air hydrometeorological data. They may also be applicable to other types of observational data that are needed in establishing the baseline relationships in climate and health.

The WMO promotes the overcoming of inhomogeneity in datasets by recommended practices known as "Direct" and "Indirect". Direct practices are active as soon as they are adopted. Examples include the maintenance of a network of Reference Climate Stations, and adherence to the Global Climate Observing System's Monitoring Principles. Indirect methods are applied on historical datasets, and include the use of metadata to re-quality control the data, using reference time series, breakpoint identification, and adjustment of data. 
Procedures to limit inaccuracies in data, and to adjust inaccuracies in historical data, are described in the WMO's Guidelines on Climate Observation Networks and Systems (WMO 2003a) and Guidelines on Data Rescue (DARE). For erroneous data, the researcher can communicate with the dataset owner or manager to overcome errors in dataset identifiers, algorithms, transmission, transcription, encoding. It still may be necessary to apply DARE procedures.

Missing, incomplete or insufficient data can be the most frustrating problem for a researcher. The recommendations that follow cannot provide data for observations that were never taken, for example. If the data are missing due to a limited observing programme, data exchange policy or practice, seek the data through the WMO Permanent Representatives, through literature searches, or through institutional or academic networks. If they are incomplete due to their not having been digitized, or they have gaps due to civil conflict or disaster, or are questionable due to inhomogeneity, the National Meteorological and Hydrological Service may be able to resurrect the data through the application of procedures through the DARE project. It may be possible to have adequate results by substituting another dataset for the desired one. For example, Climate Change Detection indices can provide analyzed data that capture climatic extremes and trends (WMO 2003c). Data that are insufficient due to resolution in time, space, or parameter set may be approximated through use of remotely sensed data from Meteorological satellite, profiler, Doppler RADAR, etc. And model data that are needed at a specific location may be approximated through extrapolation of surrounding gridpoints' data.

To begin addressing health data collection and management problems, the World Health Organization began hosting the Health Metrics Network (HMN) in 2005 (WHO 2004b). The HMN operates through high level collaboration among countries, international agencies, donors and foundations, and technical experts. It was initiated with a large grant from the Bill and Melinda Gates Foundation. The objectives of the HMN are the following:

- Define and set standards for core health information platform designs, key indicators, data and analytic capacities and guidelines for intra- and international information use

- Accelerate and focus development and improvement of national Health Information Systems in developing countries

- Develop policies and strengthen systems and incentives that improve access to and use of information by local, regional, national and global constituencies

\subsubsection{Examples of Climate Applications for Human Health}

Our specific contribution ... has been to add an understanding of climate variability as a driver of both land-use change and human health and thus as an important confounding factor in understanding land use-health interactions. - M. C. Thomson et al. (2004a) 
This section explores applications in which knowledge of climate variability is used to enhance the understanding, control and treatment of a number of diseases.

\subsubsection{Onchocerciasis (River Blindness) and Its Relation to Land Use Cover Change ${ }^{5}$}

This disease is sensitive to climate variability, especially in the macro sense of the seasonal distribution of its vectors and the availability and viability of vectors' habitats. However, the purpose of discussing it here is to set the stage for an exploration of the complexities of the contributions and feedbacks among ecological and social systems that make the development of climate applications for health so interesting.

Onchocerciasis was a neglected disease, but it has become more devastating since the 1970s. Its effects are greatest on the rural populations of the West African savannah living near fast-flowing rivers. The vector is the blackfly which needs to have a particular type of underwater vegetation to lay its eggs. At the initiation of the Onchocerciasis Program (OCP) in 1974, some savannah villages close to river valley habitats of the blackfly vector were suffering severely, with $60 \%$ adults infected, and 3-5\% already blind. Many villages had been completely abandoned. At the peak of the OCP control activities in 1986, the estimates were that 30 million were affected and 2.4 million were infected. The Programme's 20-year eradication programme put the disease under virtually total control in 11 countries in West Africa. Resettlement occurred rapidly in villages that had been abandoned.

There are two species of the fly, and two ways the pathogen works in humans. In the savannah areas, there is a prevalence for the blinding form of the disease. In the deep forest, however, there is more likely to be a skin disease, which is much less problematic than blindness. The causal agent is the filarial worm - a segmented, small worm. The vector is the savannah species of blackfly that transmits the filarial worm to humans through its bite, and is mainly controlled by insecticide sprayed on savannah rivers. In the epidemic areas, the vector control for humans is supplemented by an oral drug - ivermectin tablets - that act on the filarial worm.

The spraying could be made ineffective by changes in climate that would increase the flow of rivers sufficiently to wash away insecticide without washing out the fly's habitat. But, the control programme has benefited from climatic knowledge and prediction of the monsoon winds and associated rainfall patterns, which has been used to plan the timing, locations, and type of insecticide used (Thomson et al. 2004b).

\footnotetext{
${ }^{5}$ Drawing heavily on work reported in Thomson et al. (2004a).
} 
Intentional deforestation to convert areas for agriculture and human habitation resulted in savannah flies moving to newly habitable areas and bringing the blinding form of disease. Between 1973 and 1990, the studied area experienced a 10\% increase in urban habitat, $18 \%$ increase in savannah area, $11 \%$ decrease in degraded forest, and $17 \%$ decrease in dense forest. This caused significant changes in the habitat for the fly and the type of fly that brings the blinding disease, and these had serious impacts on the growing numbers of humans in the region. From 1975 to 1980 , the river blindness variety of the disease was only prevalent in $10.5 \%$ of the area. By 1997, it had virtually doubled. The existence of the effective control program meant that human settlement could move into other, uncontrolled areas, i.e. previously vacant land, and it did so with vigor. In 1973 along the river, $5 \%$ of the area was cultivated. In $1983,30 \%$ was cultivated; by $1993,70 \%$ was cultivated, and with the increase in cultivation and human habitation along the rivers humans were being increasingly exposed. Humans were also changing how water got to the river, which affected the habitat sites for the vectors.

By the mid-1990s the method of control of the disease had swung from one that relied predominantly on spraying insecticide on the vector habitats (as had been done under the OCP), to the oral drug (ivermectin) treatment of humans (the method employed in the African Program for Onchocerciasis Control (APOC) that followed after the OCP). But, expansion of the control efforts into forested areas resulted in severe adverse reactions and death among patients taking the drug, which was associated with ivermectin. Distribution of the drug was impeded because control organisations did not want to increase the problems of the reaction of the drug.

Why was it happening, and what could be done? The path to the answer to the first part of that question lay beyond onchocerciasis, to Loa loa - another disease that is transmitted by a different vector. It was shown that people infected through bites from the chrysops fly and contracting Loa loa were the ones having serious reactions to the ivermectin. The drug became ineffective not because it couldn't handle the onchocerciasis, but because, in the presence of the Loa loa in the body (a less serious disease), it resulted in severe reaction.

\subsubsection{Loa Loa $^{6}$}

Loa loa is now the major issue $-20 \%$ of the population that is subjected to both onchocerciasis and Loa loa is at risk of adverse reactions to ivermectin. That means that, in terms of onchocerciasis, medical professionals are having to analyze who will get severe reactions, and they are working on alternative methods of introducing the drug ivermectin or other treatments.

\footnotetext{
${ }^{6}$ Drawing heavily on work reported in Thomson et al. (2004a, c).
} 
The APOC gave high priority to mapping the spatial distribution of loiasis, so that it could modify its approaches to treatment and enhance the surveillance methods. Looking at all of Cameroon, for example, meant a great area to have to cover. But by focusing on areas where a $20 \%$ or greater prevalence was predicted, they could find where the Loa loa presence was dramatically increasing. Extensive study began with mapping the distribution of environmental factors that influenced Loa loa distribution. The mapping showed that the Chrysops fly habitat was associated with fringe areas between the dense forest and its borders with cultivated areas, where the fly could live in the high crowns and the larval stages could grow in wet, organically rich and muddy low-lying areas. That is a vastly different habitat from that of the blackfly of onchocerciasis, which needs fast-moving water.

A risk map was developed using data from Cameroon. Considerable prevalence data was available, through the Centre Pasteur of French Research for Development organisation (IRD). Newly available environmental data included imagery from the SPOT sensor and the Synthetic Aperture Radar sensor (SAR). The available population data were extensive - over 14,000 individuals from 95 villages over period of 10 years - age, sex, presence or absence of Loa loa, and the amount of blood taken for examination - and were factors for the regression analysis. Data on the village - latitude and longitude from the ordinance survey map or a Global Positioning System - were used to anchor epidemiological data. Population density, normalized difference vegetation index data (NDVI) from SPOT and SAR, and altitude from the US Geological Survey's Digital Elevation Model were obtained. The NDVI satellite data show the seasonal and inter-seasonal variations in the vegetation, which provides information on the status of the vector habitat as it responds to climatic variations. The data also correlate well with the changes in the distribution of the vectors. But, the NDVI data has $1 \mathrm{~km}$ resolution, while some forest galleries that are important in looking for vector habitat are only $50 \mathrm{~m}$ wide. Synthetic aperture radar resolved to $100 \mathrm{~m}$ was used and the finer resolution gave more detail in looking at forest areas.

Using the environmental data and considerations of age and gender, a logistic regression model was used to map the spatial prevalence of the disease. Of particular concern are areas where the prevalence exceeds $20 \%$, and in only a very few locations did the prevalence exceed this threshold when the model indicated lower levels of risk. The model has been applied to map risk of the disease in the Cameroon region, the Sudan, and Ethiopia.

\subsubsection{Meningococcal Epidemic Meningitis ${ }^{7}$}

Meningococcal Meningitis transmission is by direct droplet contact. This disease only exists in the nose and throats of humans. Twenty- to forty percent of the West

\footnotetext{
${ }^{7}$ Drawing heavily on work reported in Thomson et al. (2004a).
} 
African populations that are affected are symptomless carriers - they have it in nasal cavities in membranes but exhibit no symptoms. The seasonality and interannual variability of the disease are related to the proportion of clinical infections that get strong enough for patients to begin seeking treatment, compared to the sub-clinical infections. It is the strength of the infection, and the cycle of spreading the disease to another, that is more important to researchers, rather than the behavior of the persons in transmitting the disease.

The disease is sensitive to climate variations, especially on the seasonal scale. Epidemics typically reach their peak at the height of the dry season and diminish once the rainy season commences. If vaccination starts before the peak, the disease can be managed better, but that is costly and depends on well maintained surveillance and response mechanisms. An alternative is to vaccinate ahead of the onset of cases, but while that may be cost-effective it is difficult to implement.

There is a concentration of geographical distribution and seasonal occurrence in the Sahel zone of Africa - the risk factors are dry, dusty conditions, which increase the risk of the disease. The main apparent contributor is land use and land use change, where cultivation stirs up the soil. The fine airborne dust $(1 \mu)$ is a factor in the disease, as particles can reach well into the lungs.

Modelling through the Meningitis Forecasting Project for Africa showed that absolute humidity and land cover are reliable indicators to distinguish between areas with high and low risk of epidemic events. Other important indicators include population density, dust and soil type. Meningitis epidemics have been shown to be influenced strongly by low absolute humidity and dusty conditions outside the tropics as well. Analysis by the Meningitis Forecasting Project for Africa shows that the risk of Meningitis epidemics in Africa is concentrated in certain specific regions, and that the environment and particularly the climate variations are strong influences on where and when they will occur. The high predictive value of the model developed through the Project showed that an environmental model can be instrumental for policy makers in understanding the distribution of meningitis epidemic risk across Africa.

The model also has the potential to be useful in a Meningitis Early Warning System. It is able to resolve environmental components to inter-annual variability with respect to the different times of the year in which they are important. However, much work remains to be done, especially on the ways that the environmental and other factors influence the onset and extent of epidemics.

Changes in the spatial and temporal distribution of diseases result from changes in population, climate, land use, economy, and social structure, among others. Health decision makers often require simple solutions to complex problems. It is important to work with policy makers to understand their decision frameworks, to initiate the dialogue as to the value of specific information and to develop their use of uncertain information. 


\subsection{Early Warning Systems}

Early Warning Systems (EWS) are a common approach in many activity areas to preparing to deal with anticipated problems when there is still time available to respond to and to mitigate those problems. According to the Department of Early Warning and Assessment (DEWA) of UNEP the fundamental roles of Early Warning Systems are to analyse and assess trends, to provide policy advice, to provide early warning information on threats, and to catalyse international cooperation based on best-available scientific and technical capabilities. A scan of the web reveals Early Warning Systems for breast cancer, national development projects, Internet and credit card fraud, war and conflict outbreak, the energy and water balance of the earth's surface, paedophilia, volcanic eruptions and earthquakes, and many more. One evolving EWS that has attracted much recent media attention at the time of writing is the Indian Ocean Tsunami EWS, instituted following the 26 December 2004 event. Many of these systems listed above naturally involve no element of climate, and frequently in the past those that do incorporate climate as a component have issued warnings based only on climate observations and not on predictions per se, a situation that is now changing rapidly as the potential benefits of predictions are becoming recognised. Famine, drought, heat, and health-related EWSs are examples of those that include climate components.

All Early Warning Systems tend to follow the same basic model. Relevant events known to be associated through experience and observation with the issue of concern, say famine, are monitored and interpreted. Actions are then taken once pre-determined trigger points are reached. In some cases there may be only a single trigger point, such as with a tsunami system when an earthquake satisfying basic criteria and/or evidence of an existing tsunami will trigger an "evacuate" instruction, whereas in other systems several trigger levels may exist instigating progressively more urgent responses. In all cases the idea is simply to use knowledge of precursors, together with efficacious monitoring, to provide as much warning as possible that potentially adverse impacts, such as declining food stocks or conditions suitable for a malaria outbreak, are in the course of development. Early Warning Systems in general do not predict that specific adverse impacts will occur in due course, but merely extend preparation time compared to systems that respond only once impacts have been recognised, at which stage it is often too late to take remedial actions. Systems that maintain watches for on-the-ground signs that impacts, perhaps famine, are occurring in reality, but without providing warning, are known as Early Detection Systems (EDS); EDS's are frequently used to complement EWS's. There is a recent trend, however, to incorporate predictions, including weather and climate, within EWS's in order to help focus the warnings.

A new concept of early warning has been developed using the ideas of chemical theory, in particular the terms 'hotspot' indicating a reaction that might become unstable, 'flashpoint' at which the reaction begins but may still be reversed, and 


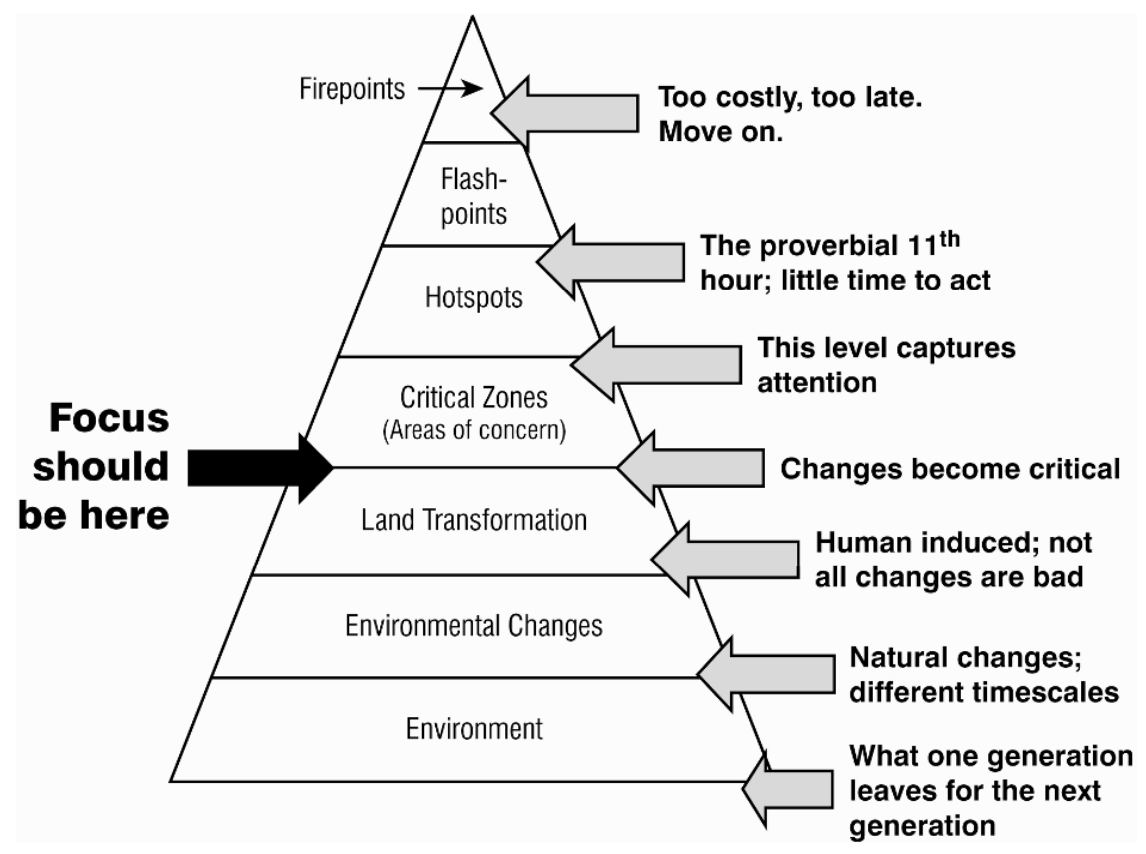

Fig. 13.5 Diagrammatic representation of the various stages through which environmental changes might translate to become firepoints. Preventative action is best undertaken at the 'critical zones' level rather than await the creation of hotspots and, later, flashpoints within them

'firepoint' at which the reaction cannot be reversed. Although Fig. 13.5 has been prepared on this concept within the context of environmental changes it is readily revised within any other context. Within the layers of Fig. 13.5 an EDS might be designed to operate within known critical zones, and in particular hotspots, to indicate that a flashpoint has been reached. An EWS would operate throughout to monitor the changing situation and to interpret information in terms of the likelihood that hotspots will translate to flashpoints.

At one time there was a remarkable proliferation of Early Warning Systems in developing countries, often with individual NGO's, International Development Agencies, UN Agencies and national Government Departments having their own systems, each with their own specific, but at times duplicative, objectives. Some consolidation has taken place in recent years, frequently under UN bodies including UNEP DEWA, such that duplication and differential triggering have been reduced. Examples of major Early Warning System activities include:

- The Humanitarian Early Warning System, HEWS, ${ }^{8}$ organised by the UN World Food Programme on behalf of the IASC (Inter-Agency Standing Committee),

\footnotetext{
${ }^{8}$ See: http://www.hewsweb.org
} 
which represents a large number of UN Agencies, various Inter-Government Agencies, NGOs and other Institutes - HEWS provides a one-stop web source for droughts, floods, storms and other weather events, locust invasions, seismic events, avian influenza, plus others on an as-needed basis.

- The Global Information and Early Warning System, GIEWS, ${ }^{9}$ of the UN Food and Agriculture Organization, and the Famine Early Warning Systems Network, FEWS NET, ${ }^{10}$ run by the US Agency for International Development together with several other US Government agencies, both with a focus on food security in the developing world.

- The Malaria Early Warning System, MEWS, coordinated by the UN World Health Organization, that developed from the Roll Back Malaria project.

Most Early Warning Systems have similar generic requirements:

- A good quality archive of historical data covering as many aspects relevant to the issue of concern as possible, in all necessary spatial and temporal detail; this archive should include all factors that relate to vulnerability in regard to the issue of concern and may therefore extend beyond information just on the events of interest to include, say, population data, land use data, economic data, climate data, and so on.

- An understanding of the historical data in terms of its relationships to, and hence its information content with regard to producing warnings for, the issue of concern.

- Agreed approaches to recognising trigger points and to responding to these in established manners, preferably with an experience-base assisting in establishing best practice.

- An adequate monitoring system for all relevant data at appropriate temporal and spatial resolutions.

- Systems for accessing monitoring data and for broadcasting warnings to decision makers within time constraints appropriate to the issue of concern.

- Institutional support at all necessary levels for maintaining the system and for responding to the warnings.

Each of the requirements in the above list presents its own specific challenges, particularly in regions where data are lacking, or data archiving is inadequate, or the necessary research is incomplete. But the final bullet in the above list is perhaps the most important, as without appropriate institutional support the potential benefits of any EWS may not be realised; care needs to be taken in any demonstration project that institutional constraints are recognised and addressed.

\footnotetext{
${ }^{9}$ See: http://www.fao.org/WAICENT/faoinfo/economic/giews/english/index.htm

${ }^{10}$ See: http://www.fews.net
} 
Prediction per se, and seasonal to interannual climate prediction in particular, does not currently form a component of many Early Warning Systems, although on the climate side developments in the understanding of ENSO have enabled benefit to be gained from knowledge of the canonical expressions on temperatures, rainfall, storms, etc. during different phases of ENSO. However such knowledge can be used inappropriately when specific ENSO events produce non-canonical responses, as occurred around some parts of the Indian Ocean basin during the 1997/98 El Niño (see Figs. 1.1 and 6.10). Seasonal climate prediction, rather than use of climatology, is preferential, but so far has not been employed to the extent that it might. Perhaps one reason for the relative lack of use of climate prediction information, despite the evident advantages of its employment, is absence of clear demonstrations that predictions at their current state of development will benefit warnings. Further these predictions may lack the spatial and temporal specificities considered desirable to improve EWSs.

One area in which progress has been made in the incorporation of seasonal to interannual rainfall prediction is in MEWS, the Malaria Early Warning System, where additional Forums over and above the RCOFs have been trialled in southern Africa with regard to converting climate predictions into malaria outbreak predictions. As detailed in Section 13.4.2, there is a close link between both climate and climate variability with malaria incidence, both spatially and temporally, but it is in the epidemic areas where climate is only intermittently conducive to the spread of the disease that prediction would be of greatest benefit. Modelling studies have demonstrated that malaria incidence is, to an extent, predictable based on climate inputs alone, and thus prediction might be used either independently or within the structure of an EWS. Pilot studies within the southern African region have taken the approach of introducing predictions within the structure of a MEWS, as illustrated in Fig. 13.6.

The bottom row in Fig. 13.6 illustrates across 4 years the weekly incidence of malaria morbidity and mortality at a location within an epidemic zone, with the black line indicating historical averages. In the row above are shown rainfall observations for the 4 years, together with, in black, the climatology. Of interest, naturally, in this epidemic area is the fourth year, during which a malarial outbreak was preceded by above-average rainfall that established breeding sites for the vectors. Flag 3 (see top row), a trigger point obtained through an EDS, provides confirmation that an outbreak is in progress during this fourth year, but offers on its own rather limited preparatory opportunities. An EWS, that had not only suggested increasing vulnerability of the population to an outbreak through the earlier years (because of reduced resistance resulting from a period of limited mortality/morbidity accompanying rainfall around or below average - second row), but that also recognised the relatively high rainfall of the fourth year, might have offered a trigger point at Flag 2 at the onset of the heavy rains, with a few weeks' preparatory advantage over Flag 3.

Seasonal rainfall prediction, as in the third row, might offer the further months of preparatory time associated with the trigger point of Flag 1. In practice the 


\begin{tabular}{|c|c|c|c|c|}
\hline & Year 1 & Year 2 & Year 3 & Year 4 \\
\hline $\begin{array}{l}\text { (1) Pre-season assessment } \\
\text { (2) Rainy season assessment } \\
\text { (3) Malaria season assessment }\end{array}$ & (1) (2) (3) & (1) (2) (3) & (1) (2) (3) & (1) (2) (3) \\
\hline \multicolumn{5}{|l|}{ Vulnerability } \\
\hline \begin{tabular}{l|l} 
High & \\
Medium & \\
\cline { 2 - 3 } &
\end{tabular} & & & & \\
\hline \multicolumn{5}{|l|}{$\begin{array}{l}\text { Seasonal climate forecasts } \\
\text { (updates available monthly) }\end{array}$} \\
\hline \multicolumn{5}{|l|}{$\begin{array}{l}\text { Above } \\
\text { Normal } \\
\text { Below }\end{array}$} \\
\hline \multicolumn{5}{|l|}{$\begin{array}{l}\text { Rainfall monitoring } \\
\text { (or other environmental } \\
\text { variable monitoring) } \\
\text { (e.g., 10-day data from satellite } \\
\text { or meteorological station) } \\
\text { black line = long-term mean }\end{array}$} \\
\hline $\begin{array}{l}\text { Malaria morbidity / mortality } \\
\text { monitoring at sentinel sites } \\
\text { (e.g., weekly case numbers) } \\
\text { black line = long-term mean }\end{array}$ & & & & \\
\hline
\end{tabular}

Fig. 13.6 Example of the manner in which a malaria Early Warning System might work using seasonal climate predictions (middle row) in an epidemic area. Malaria incidence is given in the bottom row with observed rainfall above; respective climatologies are shown as black lines. Vulnerability of the population is shown via a traffic light approach in the second row, while triggers are shown in the top row. See text for full details

decision making in this case is slightly more complex than is suggested in Fig. 13.6 as the probabilistic seasonal rainfall predictions shown have inflated levels of skill, and in reality the category with the highest probability is not likely to occur as frequently as indicated. Nevertheless this pilot study illustrates the potential benefits offered by seasonal to interannual prediction within the context of Early Warning Systems.

\subsubsection{Health Early Warning Systems}

\subsubsection{Dengue Fever Early Warning in Indonesia}

Dr Dana Focks (Focks 2003) reported on developments of an early warning system for dengue and dengue hemorrhagic fever in Southeast Asia. The early warning system predicted dengue prevalence in March to May in Yogyakarta, 
Indonesia. Using sea surface temperature data from meteorological satellite and data from the epidemic from 1987-1989 to develop a statistical model, the Dengue Early Warning system with 3 months' lead time was predicting correctly and had one error in the prediction for the year 1992 (a false positive): the model gave a probability of 0.64 of "epidemic" and 0.36 of "no epidemic". The WHO and PAHO formerly had promoted insecticide aerosols for control of mosquitoes - a government based approach that was costly and didn't work, and was abandoned. Then in the 1990s the new approach became "community-based source reduction", with the goal to clean or eliminate open containers (e.g. discarded tires, empty oil drums) that fill with water, which are a habitat for the mosquitoes that carry dengue. But, without a strong, direct government push, the recommendations were not followed through, which meant that there was no effective control with that approach either. The latest strategy is to use a climate-based Early Warning System to focus control on the containers most likely to provide adequate habitats, for example, a particular class; or, all those abandoned in selected sites, e.g. public lots and gathering rainwater, etc., to help focus the cleanup efforts.

\subsubsection{Heat Health Warning Systems}

Two major activities are underway to develop guidelines on heat health warning systems (HHWS). The World Meteorological Organization through its Commission for Climatology is studying universal thermal heat indices and heat health warning systems, with the goal of issuing guidelines that will help all WMO Members to establish warning systems to protect their populations from extreme heat events (WMO 2004). At the heart of most HHWS are forecasts of dangerous heat conditions, which can be based on:

1. Single meteorological variables such as air temperature or relative humidity. Relative humidity is often not used effectively, but temperature does contain information about the thermal environment.

2. Simple thermal indices (historic) as, e.g. the Heat Index. These are believed to have limited relevance and limited reliability.

3. Weather classifications (holistic approach). This approach has been shown to be successful in heat/health studies. The technique requires the development of a synoptic or weather type classification that can, depending on the level of sophistication, be data and analysis intensive. Furthermore, synoptic or weather types, as is the case for human energy-based biometeorological indices, can never be verified, as they are statistical or numerical constructs. This contrasts with conventional meteorological variables, as forecast values of these can be compared with actual observed values.

4. Heat budget models, such as the Universal Thermal Climate Index (UTCI). These are thermophysiologically relevant, consider the complete heat exchange 
conditions, and are valid for all thermal environments (both heat and cold). Such procedures are able to fulfill the precondition that the same value of an index always means the same for the human body, independently from the combination of the single values of the meteorological input parameters.

The other major activity is the Watch Warning System work package of the Assessment and Prevention of Acute Health Effects of Weather Conditions in Europe (PHEWE) project and the associated EuroHeat project (considering the utility of seasonal climate forecasts), under the of the Fifth Framework Programme, funded by the European Union (WHO 2004a).

\subsubsection{The Malaria Early Warning System: Malaria Incidence - Climate Relationships in Botswana}

In this section, a step-by-step analysis is presented of the relationship between the annual incidence of confirmed malaria in Botswana, and a country-wide average of rainfall during the peak rainfall season. The results are then used to make a prediction of malaria incidence. The analysis is based on previous research by Thomson et al. $(2005,2006)$, but updates the data to 2005 . The reader should be able to repeat, as an exercise, the analyses using the data presented in the tables.

Table 13.1 shows a set of annual total confirmed and unconfirmed malaria cases in Botswana for the 24-year period 1982-2005, together with the estimated population for the country. Any analysis of trends in malaria (or any other disease) should take account of changes in the population since the total number of people infected will almost inevitably increase if the total population increases. It is more informative to consider the trends in the proportion of people affected by a disease. For example, since the population of Botswana increased by approximately $80 \%$ over the 24 -year period, the total number of malaria cases would have to increase by more than $80 \%$ to indicate that the disease had become more widespread. The standard way of indicating the proportion of people affected by the disease is to divide the number of cases by the total population. This number is known as the incidence. The incidence is often multiplied by 1,000 to indicate how many people out of a typical sample of 1,000 people were infected with malaria. The confirmed incidences per 1,000 are illustrated in Fig. 13.7.

Figure 13.7 indicates that outbreaks of malaria seem to have occurred at intervals averaging about 4 years. These outbreaks were then followed by exponential declines in incidence. This pattern is characteristic of a population's evolving immunity: after an outbreak, immunity is built up, and incidence declines, but with the consequent decreased exposure to the disease, immunity is lost, and the disease can re-occur at a potentially devastating extent. 
Table 13.1 Annual confirmed and unconfirmed malaria cases in Botswana for 1982-2005, together with the estimated total population

\begin{tabular}{cccc}
\hline \multicolumn{3}{c}{ Malaria cases } \\
Year & Confirmed & Unconfirmed & Population \\
\hline 1982 & 85 & 332 & $1,019,690$ \\
1983 & 161 & 1,167 & $1,051,227$ \\
1984 & 320 & 1,831 & $1,083,739$ \\
1985 & 628 & 1,867 & $1,117,256$ \\
1986 & 1,437 & 2,994 & $1,151,811$ \\
1987 & 326 & 1,228 & $1,187,434$ \\
1988 & 9,013 & 21,587 & $1,224,159$ \\
1989 & 5,398 & 14,842 & $1,262,019$ \\
1990 & 1,916 & 8,457 & $1,301,051$ \\
1991 & 1,783 & 12,012 & $1,326,796$ \\
1992 & 415 & 4,293 & $1,358,554$ \\
1993 & 14,615 & 40,722 & $1,391,073$ \\
1994 & 5,335 & 24,251 & $1,424,369$ \\
1995 & 2,271 & 16,451 & $1,458,463$ \\
1996 & 25,641 & 80,004 & $1,493,373$ \\
1997 & 19,811 & 100,579 & $1,529,118$ \\
1998 & 5,810 & 59,623 & $1,565,719$ \\
1999 & 12,754 & 72,803 & $1,603,196$ \\
2000 & 8,056 & 71,555 & $1,641,570$ \\
2001 & 4,716 & 48,281 & $1,680,863$ \\
2002 & 1,283 & 28,907 & $1,721,096$ \\
2003 & 1,830 & 23,657 & $1,762,292$ \\
2004 & 3,453 & 22,404 & $1,804,475$ \\
2005 & 1,738 & 14,019 & $1,847,666$ \\
\hline
\end{tabular}

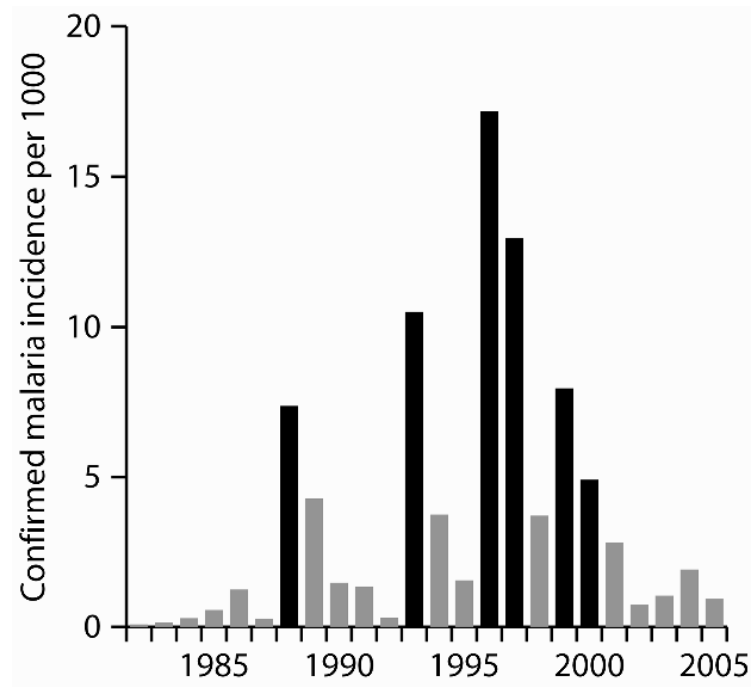

Fig. 13.7 Annual confirmed malaria incidences per 1,000 population in Botswana for 1982-2005. The black bars indicate epidemic years: those in which the incidence exceeded the upper quartile 
If an outbreak is severe, it is called an epidemic. Epidemic years are formally identified as years in which incidence is higher than the upper quartile. The upper quartile defines the level of incidence that is exceeded on average once in every 4 years. The epidemic years are highlighted as black bars in the graph, and they occurred in 1988, 1993, 1996, 1997, 1999, and 2000. The worst epidemic occurred in 1996, and seemed to be part of an upward trend that has apparently been reversed. This upward trend is attributable, in part, to changes in the resistance of the malaria parasite to drugs, and represents an increase in vulnerability of the population to the disease. Similar vulnerability trends have been widely reported in other parts of the continent and beyond.

Changes in malaria control policy were implemented in 1996, and, if effective, would be evident in the data for 1997 and later. The policy intervention does appear to have been effective in halting, or even reversing the upward trend. However, the simplest way to test the effectiveness of the intervention is to consider its impact on the ratio of unconfirmed to confirmed malaria cases. Since the incidence of unconfirmed malaria consists of cases of malaria-type symptoms that could just be cases of fever, the ratio of unconfirmed to confirmed incidence is likely to have increased if the changes in malaria control have been effective. In Fig. 13.8 the confirmed and unconfirmed incidences are compared for pre- and post-policy change years. The incidences for 1997 onwards are shown in grey, and there is a clear increase in the ratio of unconfirmed to confirmed cases represented by the displacement of the grey markers to the right of the graph. The intervention therefore appears to have been effective.

Since most statistical tests assume that the data being analysed are normally distributed, the incidence data should ideally be transformed because the annual values are strongly positively skewed (skewness is approximately 1.8). Taking the

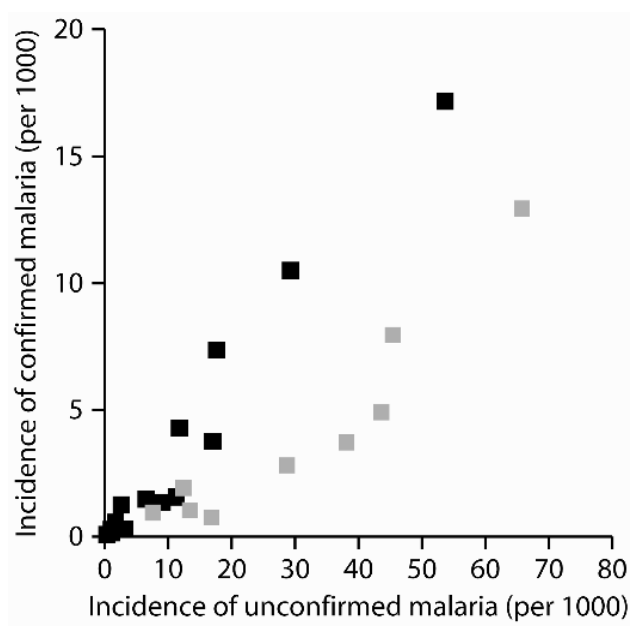

Fig. 13.8 Annual confirmed and unconfirmed malaria incidences per 1,000 population in Botswana for 1982-1996 (black) and 1997-2005 (grey) 
logarithm of the incidence eliminates the positive skewness, and even introduces a slight negative skew (skewness is approximately -0.3 ). The log-transformed incidence is therefore a more appropriate value than the incidence for performing statistical analyses.

Epidemic malaria generally occurs in one of two areas: semi-arid areas where insufficient rainfall usually limits breeding areas for mosquitoes; and highland areas where cold temperatures can severely restrict the breeding cycle of the malaria parasite. In the "desert fringe malaria" areas, where rainfall deficiencies typically restrict the occurrence of malaria, occasional seasons of heavy rainfall can result in epidemic malaria because of the increase in mosquito breeding sites. Botswana is a semi-arid country, and most of the rainfall occurs in the summer months December-February (Fig. 13.9, black bars). The malaria incidence peaks about 2 months later (Fig. 13.9, grey bars). Rainfall varies considerably from year to year in Botswana (Table 13.2), and so, epidemic years may be most likely to occur after a good rainfall season.

Given the vulnerability trends already mentioned, as well as the effects of the policy intervention of 1996, a simple correlation between the rainfall and the log malaria incidence would not give an accurate indication of the strength of the effect of rainfall on epidemic risk. A regression model is to be used to estimate the influence of climate, but it is necessary to account for these known non-climatic influences in the model in order to estimate the climate's influence more accurately. Consider first the policy intervention. There are a number of possible effects of this intervention:

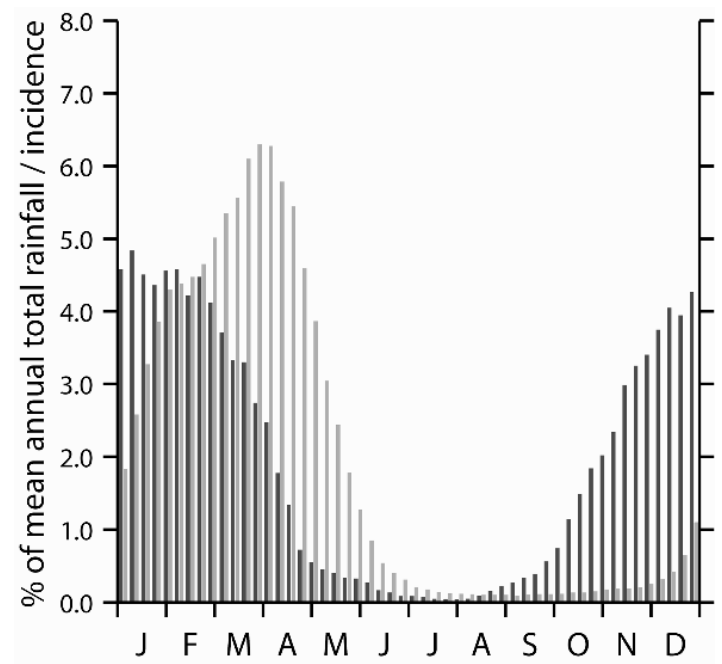

Fig. 13.9 Averaged weekly confirmed malaria incidences per 1,000 population in Botswana (black bars) and averaged weekly rainfall totals 1997-2005, as percentages of the mean annual totals. The weekly averages are filtered using a 5-week running mean 
1. The background incidence (as measured by the mean) may been have changed

2. The vulnerability trend may have been changed

3. A combination of the two previous effects may have occurred

4. There may have been no discernible effect at all

To test these possibilities, additional variables need to be included in the regression model. Firstly, an indicator variable (a series of 0 s and $1 \mathrm{~s}$ ) is defined that indicates years in which the intervention has occurred. This variable will therefore equal 0 up to 1996, and 1 from 1997 onwards. In a regression model, this variable can be used to represent a change in the background incidence (option a). An additional new variable is required to represent option $b$, but the vulnerability trend itself needs to be accounted for first. The vulnerability trend can be represented as a simple linear trend component by including the year in the regression model. The possibility of a modified trend can then be calculated by superimposing an additional trend component on the long-term vulnerability trend, starting only in 1997. This modified trend is incorporated by a variable that is obtained by multiplying the year by the indicator variable. Thus, three new variables are included that describe the possible effects of trends in vulnerability, and the effect of the policy intervention on both the trend and on the mean incidence.

Table 13.2 December-February rainfall (mm per day) averaged over Botswana for 1981/822002/03. The Climate Prediction Center Merged Analysis of Precipitation (CMAP) data were averaged across the 20 grid points between $17.5-27.5^{\circ} \mathrm{S}$ and $17.5-30.0^{\circ} \mathrm{E}$ as approximately representing Botswana

\begin{tabular}{cc}
\hline Year & Rainfall \\
\hline $1981 / 82$ & 1.81 \\
$1982 / 83$ & 1.81 \\
$1983 / 84$ & 1.93 \\
$1984 / 85$ & 2.46 \\
$1985 / 86$ & 2.37 \\
$1986 / 87$ & 1.89 \\
$1987 / 88$ & 3.67 \\
$1988 / 89$ & 3.93 \\
$1989 / 90$ & 2.44 \\
$1990 / 91$ & 2.98 \\
$1991 / 92$ & 1.70 \\
$1992 / 93$ & 2.48 \\
$1993 / 94$ & 3.33 \\
$1994 / 95$ & 1.90 \\
$1995 / 96$ & 3.80 \\
$1996 / 97$ & 3.56 \\
$1997 / 98$ & 2.19 \\
$1998 / 99$ & 2.66 \\
$1999 / 00$ & 4.88 \\
$2000 / 01$ & 2.31 \\
$2001 / 02$ & 1.76 \\
$2002 / 03$ & 2.23 \\
$2003 / 04$ & 2.48 \\
$2004 / 05$ & 2.37 \\
\hline
\end{tabular}


Before proceeding, one additional new variable should be considered. In other areas excess rainfall has been found to impact mosquito populations negatively through the destruction of breeding sites. Independent research results indicate the existence of a quadratic relationship between rainfall and malaria incidence: an increase in the mosquito population, and hence the epidemic risk, with an increase in rainfall will only occur up to a certain point; if there is too much rainfall the risk of an epidemic may decline. To consider this possible effect of excess rainfall, an additional variable representing rainfall squared is included.

Five explanatory variables are therefore to be included in the model: rainfall, rainfall squared (to account for the possible effects of too much rain), year (to represent the vulnerability trend), year from 1997 onwards (to represent the effects of the policy intervention on the vulnerability trend), and an indicator variable (to represent the effects of the policy intervention on the background incidence). The results of the regression model are shown in Table 13.3. The partial $t$-statistics for all the regression parameters are well above 2.0, indicating that all five variables explain a significant proportion of the total variance at a $95 \%$ level of confidence. The coefficients for the two climate variables describe an inverted $u$-shape (because the parameter for rainfall squared is negative, -0.26 ), confirming that excess rainfall may result in a decrease in malaria incidence. The vulnerability trend was reversed by the policy intervention (the intervention parameter of -0.16 is stronger than the vulnerability trend of 0.07 ), but the positive coefficient for the effect of the intervention on the mean incidence (322.44) seems to imply that the incidence has increased. This paradox is simply a reflection partly of the fact that there are more years in the 24-year sample prior to the intervention than following it, and partly of a discontinuity in the trend line.

Table 13.3 Regression parameters, standard errors, and partial t-statistics for estimating log annual confirmed malaria incidence for Botswana for 1982-2005

\begin{tabular}{|c|c|c|c|c|c|c|}
\hline & \multirow[t]{2}{*}{ Intercept } & \multirow[t]{2}{*}{ Rain } & \multirow[t]{2}{*}{ Rain $^{2}$} & \multirow[t]{2}{*}{ Vulnerability } & \multicolumn{2}{|c|}{ Intervention } \\
\hline & & & & & Mean & Trend \\
\hline Parameter & -148.85 & 2.00 & -0.26 & 0.07 & 322.44 & -0.16 \\
\hline $\begin{array}{l}\text { Standard } \\
\text { error }\end{array}$ & 30.41 & 0.42 & 0.07 & 0.02 & 72.92 & 0.04 \\
\hline $\begin{array}{l}\text { Partial } \\
\text { t-statistic }\end{array}$ & 4.89 & 4.77 & 3.96 & 4.76 & 4.42 & 4.42 \\
\hline
\end{tabular}

Using the results in Table 13.3, the annual log incidences that can be attributed to the vulnerability trend and to the effects of the policy intervention can be calculated. The contributions from these non-climate variables are obtained by using the regression parameters from the Table for these variables only. These contributions can then be subtracted from the observed incidences so that the effects of the vulnerability trend and the policy intervention are removed. It is important to estimate the regression parameters for these non-climate variables while including the climate variables in the model because it is possible that part of the 
observed trend up to, and after, 1996, and any change in the mean after 1996 are partly an effect of climate trends over the same period. The log incidences after removing the non-climatic effects (and after centering so that the mean over the 24-year period is zero) are shown in Fig. 13.10. The "epidemic" years have been re-identified, and are shown in black. The new years are the same as shown in Fig. 13.7, except that 1989, is classified as an epidemic year instead of 2000.

If the regression is recomputed using only the climate explanatory variables to explain the incidence data shown in Fig. 13.10, the regression parameters (except that for the intercept) are essentially unchanged, but the strength of the influence of the climate can be estimated. The climate variables explain about $75 \%$ of the variance of the adjusted incidence data. The strength of this relationship is indicated in Fig. 13.11, where the quadratic nature of the relationship is evident. The quadratic relationship appears to be primarily a result of the 1 year with almost $5 \mathrm{~mm} /$ day of rainfall (the year 2000), but the quadratic curve shown was calculated without using 2000. There is an imperceptible change in the curve if 2000 is included. The curve indicates that the risk of an epidemic is maximized when there is about $3.75 \mathrm{~mm} /$ day.

A forecast of incidence can be made given a prediction of rainfall using the results in Table 13.4. The ensemble-mean rainfall prediction for DecemberFebruary 2005/06 for Botswana from the ECMWF model was about $2.61 \mathrm{~mm} /$ day (after bias correction). This rainfall prediction converts to an estimated log incidence for 2006 of 0.14 , or an incidence of 1.15 per 1,000 . With a population of about 1.9 million, the estimated number of confirmed malaria cases would be a little

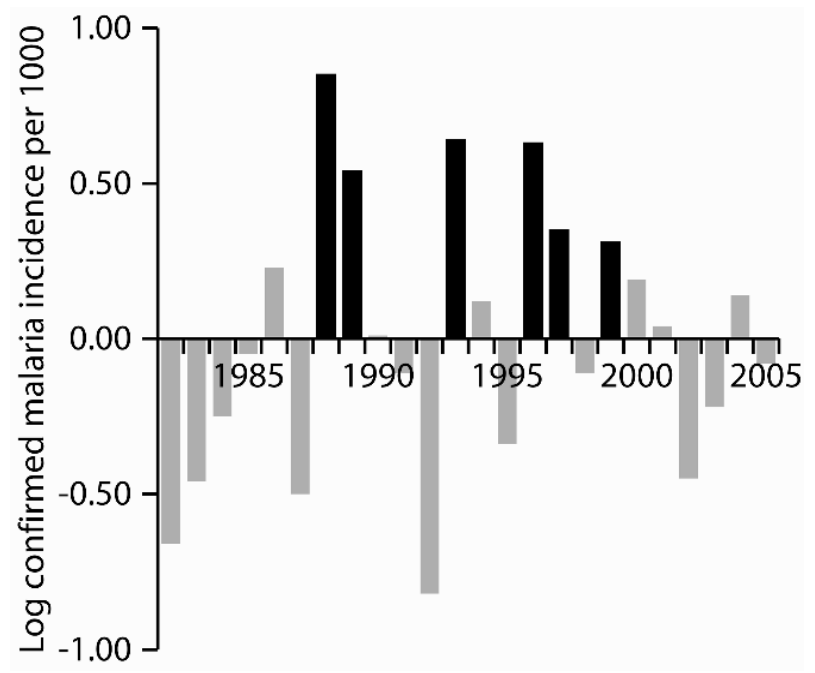

Fig. 13.10 Annual anomalies of confirmed log malaria incidences per 1,000 population in Botswana for 1982-2005, after removing the vulnerability trend and the effects of the policy intervention. The black bars indicate epidemic years: those in which the incidence exceeded the upper quartile 


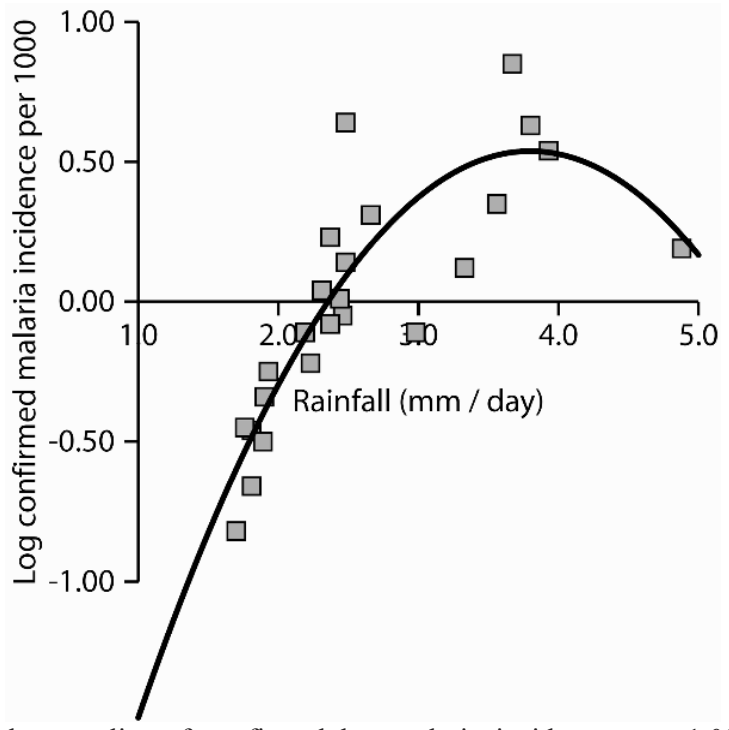

Fig. 13.11 Annual anomalies of confirmed log malaria incidences per 1,000 population in Botswana for 1982-2005, after removing the vulnerability trend and the effects of the policy intervention, and observed December-February rainfall for 1981/82-2004/05. The quadratic line was calculated without including 2000

Table 13.4 Regression parameters, standard errors, and partial t-statistics for estimating anomalous log annual confirmed malaria incidence for Botswana for 1982-2005, after removing the vulnerability trend and the effects of the policy intervention

\begin{tabular}{lccc}
\hline & Intercept & Rain & Rain $^{2}$ \\
\hline Parameter & -3.24 & 2.00 & -0.26 \\
Standard error & 0.53 & 0.37 & 0.06 \\
Partial t-statistic & 6.06 & 5.35 & 4.39 \\
\hline
\end{tabular}

under 2,200, which is not enough to qualify as an epidemic, but certainly enough to indicate an increased threat against the background of the downward trend resulting from the policy intervention. Of course, the epidemic risk should not be estimated using only an ensemble-mean rainfall prediction. One possible approach would be to use the ensemble of predictions and to obtain incidence estimates from each member. The Malaria Early Warning System described above demonstrates the effective use of combining the monitoring of weather, providing seasonal to interannual prediction of weather with respect to climatological norms, understanding the vulnerability of population, and monitoring through sentinel sites the actual incidence of the disease, to provide effective early warning of potential malaria epidemics (WHO 2001). 


\subsubsection{Establishing and Furthering Operational Climate Services for Health ${ }^{11}$}

Climate directly impacts food and fibre production, and the epidemiology of infectious diseases. Severe or repeated climate shocks can push vulnerable households into a persistent poverty trap when their individual coping responses involve divestment of productive assets, such as livestock or land. Without advanced warning, societal safety nets are costly, and difficult to mobilize and target effectively. - IRI 2005

This joint Communicable Disease Surveillance and Response, Protection of the Human Environment, and Roll Back Malaria publication was prepared with the understanding that climate based Early Warning Systems, when fully developed, do have the potential to provide increased lead times in which to implement epidemic prevention and /or control activities. Therefore their development should be encouraged, and both positive and negative experience of using such systems should be documented. - WHO 2004b

For an early warning system that incorporates climate information, we must understand the influences that climate has on human behavior, pathogens, and vectors. Certain human behaviour is strongly influenced by climate variability, and can determine the disease transmission pattern. Seasonal influences can change the balance of immunity or resistance. For example, with seasonal influenza in Europe, people tend to spend more time indoors in the winter, resulting in increasing exposures and contributing to the peak time for an outbreak of influenza. Similarly, gastroenteritis in developed countries can be associated with nonclimatic factors, as people tend be outside more in the warmer weather, cooking and eating outside and sometimes not cooking food thoroughly, or putting cooked food onto the plates that had been used for the raw food, thereby introducing pathogens.

If one is interested in developing a climate early warning system for a disease, there are some confounders that must be addressed: population vulnerability, including the likelihood that a vector will find someone within the population that is infectable, and malnutrition (the immune system is depressed). In the Kenyan western highlands, epidemics may only occur when the population has become largely non-immune. For example, if it has been a while since the last epidemic, a high proportion of the young may not have been exposed.

Dynamics of the pathogen can be highly sensitive to climate, especially those pathogens that are born outside the final host. Thresholds of temperature frequently determine the viability of juvenile stages. But pathogen dynamics can also be confounders, such as in malaria where some pathogens are becoming resistant

\footnotetext{
${ }^{11}$ The bulk of this section draws from the report, Using Climate To Predict Disease Outbreaks: A Review (WHO 2004b).
} 
to control and treatment drugs. If people are becoming infected at a higher rate, it may be due to climatic causes but it may also be due to changes in vulnerability. Climate factors such as temperature, rainfall and humidity strongly influence many of the patterns of geographical distribution and development of some disease vectors. However, the contribution of population movement and agricultural practices (e.g. deforestation and irrigation schemes) were shown to be very important in the discussion on onchocerciasis and Loa loa (Section 13.3.3): not only were people exposed to a higher risk of infection due to what was already in the savannah area, but the pathogen in the forest was converting to being a savannah type of pathogen.

It is important to rationalize the contributions of climate variability and of confounders in the variance of the aspect of disease that is the goal of an early warning system, to determine if it adds sufficient value and is practical to implement. The early warning system needs to look not only at the question of will there be an epidemic, but when an epidemic will occur. And it is important to know which of the factors will give the key information.

In developing a climate based early warning system, some perceptions may form obstacles and should be anticipated and addressed. That climate factors form only part of the set of the determinants can be reason enough for some to dismiss their value. The recipients may respect the climate factors, but not act on the early warning for other reasons. There may be insufficient interest at high levels in preventing a crisis. And, "In most cases purpose of early warning is undermined, because relief arrives too late due to poor organization at the donor level" (WHO 2004b).

What is the phase in an early warning system that is most crucial in determining its success? It is the phase following the issuance of an early warning. "Early warnings are of little use if the capacity to respond is not present" (WHO 2004b). The system must be budgeted for, the resources must be there, and all multidisciplinary collaboration must already have taken place and been successful. A preparedness plan and the organisation to apply it must exist, and each responding organisation must know its tasks, understand how their tasks fit in a well-integrated response, and have the will and commitment to implement their specific tasks.

Perhaps the most important phase of the development of an early warning system is the one that precedes it: the process of identifying the principal disease or diseases of most concern and interest, and of securing funding for the activity. The goals of an early warning system should be set in close collaboration among the climate scientists and the public health community.

\subsubsection{Framework for Developing a Climate Based Early Warning System}

From its study of existing early warning systems, the WHO determined that the framework consists of four preliminary phases, evaluate the epidemiological potential, the early warning system itself, and the response and evaluation. 
The first of the preliminary phases is to evaluate the epidemiological potential: defining what constitutes an epidemic, and looking at how the disease progresses the progression of pathogen and the vector, and human behaviour. Next, identification of the geographical location of epidemic areas is conducted, using such means as remote sensing and sentinel sites. Climatic and non-climatic disease risk factors are determined next. Then, the link between climate variability and climate predictors is quantified, and the models are constructed, taking care to account for confounders. Biological models and models of the processes in the pathogen, vector or host are incorporated to the extent that they explain how the disease aspects are affected by incremental increases or decreases in various climatic factors.

The early warning phase depends on disease surveillance, which differs from prediction in that surveillance is expressly concerned with detecting the incidence of the disease. The early warning system also incorporates the monitoring of the disease risk factors - what is the population doing, what is happening with drug resistance, what is the state and trend of the climatic factors? Monitoring requires datasets from earth observation and meteorological satellites, as well as traditional surface and upper air instruments. The last step comprises preparing model forecasts and running the health forecast model in an operational way at appropriate times.

The response phase concerns the treatment and control activities, and is tailored to the geographical and disease characteristics. It involves the treatment of people or control of vectors, and also informs the relief or containment activities, which are mostly the role of governments. The response should follow a predetermined preparedness and response plan, developed by a multi-disciplinary team - an integration of climatologists, operational meteorologists, researchers in the science of prediction, climate analysts with expertise in remote sensing, technical specialists to advise on the layers of information and analysis through GIS; and experts in epidemiology, treatment and control, population movement, land use, and policy makers. Funding may require extensive international involvement, so some representation of international funding experts may be helpful at some stages in the team.

The evaluation phase is open-ended, starting with an initial assessment and continuing with periodic assessments. Through the use of a questionnaire, interviews, or other procedures, it seeks answers to questions such as: is the early warning easy to use, are the predictions accurate, is the process cost effective, what is the best way to spend the resources for this problem? The developers and operators have to collaborate with users/stakeholders to get the answers - they are the ultimate experts in applying the control, or working with the treatments in clinics.

Securing the funding for collaborative work is complex: who takes the lead in initiating a project like this - is it the government, the climate community, control people, epidemiologists? That depends on whether it is a short-term project, or a sustainable activity, which has implications for the source of the resources. In many cases, the sustainability of such projects has depended greatly on the continuation of donor funding. 
What would be the responses that are expected once an early warning is issued? That would be specific to what the early warning was designed to do. In most cases an early warning system provides input information into work already being done, rather than mandating unique actions. The likely result is that the kinds of work necessary to reduce the impact of an epidemic will have a better likelihood of succeeding. And, it will contribute to the reduction of death and human suffering. 